NBER WORKING PAPER SERIES

\title{
THE SHORT AND LONG-RUN EFFECTS OF ATTENDING THE SCHOOLS THAT PARENTS PREFER
}

\author{
Diether W. Beuermann \\ C. Kirabo Jackson \\ Working Paper 24920 \\ http://www.nber.org/papers/w24920 \\ NATIONAL BUREAU OF ECONOMIC RESEARCH \\ 1050 Massachusetts Avenue \\ Cambridge, MA 02138 \\ August 2018, Revised May 2019
}

We are deeply grateful to Christel Saab and Sabine Rieble-Aubourg from the Inter- American Development Bank for their support in establishing the necessary contacts to assembly the administrative datasets used in the study. We are indebted to Junior Burgess and Dionne Gill from the Barbados Ministry of Education, Science, Technology and Innovation and to Andre Blair from the Caribbean Examinations Council for allowing us to access their data, their assistance, and their generosity. We would like to thank Aubrey Browne and Trevor David from the Barbados Statistical Service as well as Juan Muñoz and Ramiro Flores Cruz from Sistemas Integrales Ltd. for allowing us to introduce the necessary questions in the 2016 Survey of Living Conditions to match it with the administrative records. Francisco Pardo, Camilo Pecha, Tatiana Zarate, and Roy Muñoz provided excellent research assistance. We thank Samuel Berlinski, Damon Clark, Julian Cristia, Ofer Malamud, Norbert Schady, Laia Navarro- Sola, and Diego Vera for helpful comments. The statements and views expressed are solely the responsibility of the authors. The views expressed herein are those of the authors and do not necessarily reflect the views of the National Bureau of Economic Research.

NBER working papers are circulated for discussion and comment purposes. They have not been peer-reviewed or been subject to the review by the NBER Board of Directors that accompanies official NBER publications.

(C) 2018 by Diether W. Beuermann and C. Kirabo Jackson. All rights reserved. Short sections of text, not to exceed two paragraphs, may be quoted without explicit permission provided that full credit, including $\odot$ notice, is given to the source. 
The Short and Long-Run Effects of Attending The Schools that Parents Prefer Diether W. Beuermann and C. Kirabo Jackson

NBER Working Paper No. 24920

August 2018, Revised May 2019

JEL No. H0,I20,J0

\begin{abstract}
$\underline{\text { ABSTRACT }}$
Using meta-analysis we find that, on average, sought-after schools do not improve student test scores. A potential explanation for this result is that parents value schools that improve outcomes not well-measured by test scores. We explore this notion using both administrative and survey data from Barbados. Using a regression discontinuity design, preferred schools have better peers but do not improve short-run test scores. Consistent with the proposed explanation, the same students at the same schools have more post-secondary school completion and improved adult well-being (based on an index of educational attainment, occupational rank, earnings, and health). These long-run benefits are larger for females who also experience reduced teen motherhood. Mechanisms are explored.
\end{abstract}

\author{
Diether W. Beuermann \\ Inter-American Development Bank \\ 1300 New York Ave, NW \\ Washington, DC 20577 \\ dietherbe@iadb.org \\ C. Kirabo Jackson \\ Northwestern University \\ School of Education and Social Policy \\ 2040 Sheridan Road \\ Evanston, IL 60208 \\ and NBER \\ kirabo-jackson@northwestern.edu
}




\section{Introduction}

In many nations, there are preferred or elite public secondary schools for which there is high demand and fierce competition. To determine whether these schools tend to improve outcomes, we perform meta-analysis on publicly-available studies using quasi-random assignment to a preferred (non-charter) public school (either through lottery or selective enrollment exam). This includes studies from the United States, the United Kingdom, China, Kenya, Mexico, Romania, and others. Estimates from each of these studies for the full population (i.e., not just the subsamples with significant effects) are shown in Figure 1. ${ }^{1}$ The precision-weighted average test score impact across all studies is small and cannot be distinguished from zero.

The lack of robust achievement effects of attending preferred schools is something of a puzzle. One potential explanation is that preferred schools improve outcomes valued by parents (such as non-cognitive skills, social skills, job referral networks, adult earnings, and well-being) that are not well-measured by test-score impacts. No single paper has estimated the causal impacts of the same preferred schools on test scores and also on a broad array of medium- and longer-run outcomes. As a result, whether strong parental preferences for schools that have no impact on short-run test scores can be rationalized by these same schools improving longer-run outcomes is unclear. ${ }^{2}$ We examine this question directly using data from Barbados. We exploit quasi-random variation to estimate the causal effect of attending a preferred school on short-run exam performance. We then look at both administrative educational attainment data and survey data to estimate the causal effect of attending a preferred school on a broad set of social and economic outcomes measured in adulthood.

The Barbados data and context are well-suited for this study. At the end of primary school, students take the Barbados Secondary School Entrance Examination (BSSEE). At BSSEE registration, students submit a ranked list of preferred secondary schools to the Ministry of Education, Science, Technology and Innovation (METI), and the METI uses a deferred acceptance algorithm (Gale and Shapley 1962; Abdulkadiroğlu et al. 2005) to assign students to schools based on their choices and their test scores. The assignment rule used by the METI creates a test score cut-off for each school above which student applicants are admitted and below which they are not. This feature allows us to employ a regression discontinuity (RD) design to identify the causal effect of attending a preferred school. We use administrative data on the BSSEE, and all secondary school applications and assignments for twenty five years (1987 through 2011). To track educational outcomes, we merge these student-level BSSEE data to administrative school exam records taken at the end of secondary and post-secondary studies between 1993 and 2016. To track a rich set of

\footnotetext{
${ }^{1}$ See Borenstein et al. (2009), Appendix B, and the Inter-American Development Bank's SkillsBank (https://skillsbank.iadb.org/) for details of the meta-analysis methodology.

${ }^{2}$ Clark and Del Bono (2016) examine the longer-run effect of attending one of three elite schools in Scotland but do not examine whether the long-run impacts relate to school impacts on short-run test scores.
} 
long-run outcomes, we link the administrative BSSEE records to the 2016 Barbados Survey of Living Conditions and focus on cohorts aged 25 or older at the time of the survey. ${ }^{3}$

We show that attending a preferred school is causally associated with higher-achieving peers, more academically homogeneous peers, and smaller cohorts. However, consistent with prior work (Figure 1), we find no improvement on secondary-school exam performance (at age 16). Looking at medium- and longer-run outcomes tells a different story. In administrative data, students at preferred schools are more likely to earn a post-secondary credential (at age 18). To examine longer-run outcomes, we construct a summary index of adult well-being from the survey. This index includes educational attainment, occupational status, labor market wages, and health. Attending a preferred school is associated with considerable improvement on this long-term index (ages 25-40). These benefits are driven largely by women who experience similar health improvements as men, but enjoy larger educational and labor market improvements.

We explore mechanisms. The earnings increases for women may be mediated by having higherstatus jobs, and better social networks at preferred schools that facilitate securing these jobs. We also find reduced teen-motherhood at preferred schools- suggesting that the improved education and labor-market outcomes for females may be mediated by delayed childbearing. This is new evidence of a causal link between school quality and teen motherhood. Patterns suggest that improved health may be due to more productive habits and attitudes (rather than health care access).

Our results suggest that schools' test score impacts may not reflect impacts on adult well-being such that parents may be rational to prefer schools that have no short-run test-score impacts. This paper therefore contributes to the literature on parental preferences for schools (e.g. Black 1999; Hastings et al. 2006; Burgess et al. 2015). While economists have long proposed a causal link between educational attainment and health (Cutler and Lleras-Muney 2006; Clark and Royer 2013; Buckles et al. 2016; Malamud et al. 2018), we provide fresh evidence of a causal impact of more selective schools on health. ${ }^{4}$ This work represents the first exploration into the the causal impact of attending a preferred school on both short-run test scores and a broad array of longer-run outcomes (including health, educational attainment, occupational rank, earnings, and teen motherhood). We bring together the literatures on schools' long-run effects, the effect of elite schools on test scores, the effect of education on health, and on the multidimensionality of school output.

The remainder of this paper is as follows: Section II presents background information on the Barbados education system. Section III describes the data. Section IV outlines the identification strategy, Section V presents the results, and Section VI concludes.

\footnotetext{
${ }^{3}$ By age 25, 99 percent of all individuals had completed their formal schooling. Therefore, this population is suitable to measure educational attainment and labor market outcomes.

${ }^{4}$ Jones et al. (2011) use matching methods and find that students who attend better schools have better health. In related work, Aaronson et al. (2017) and Frisvold and Golberstein (2011) find that African Americans that had access to better schools in the early to mid 1900s had improved health outcomes.
} 


\section{The Barbados Education System}

The Barbados education system evolved from the English system. At the end of primary school (after grade 6), students register to take the BSSEE and provide a list of ranked secondary school choices to the METI. ${ }^{5}$ There are 24 public secondary schools. Between 1987 and 1995, students could rank all schools, while after 1996 students could list up to nine school choices. The BSSEE is comprised of three subjects that all students take: mathematics, English language, and an essay. The METI ranks students by their BSSEE score and gender. No other criteria are used (e.g., sibling preferences or geographic proximity). Individual school capacity by gender is pre-determined. The algorithm assigns the highest ranked student to her first choice. It then moves on to the second and treats her similarly. The procedure continues until it reaches a student whose first choice is full. At that point, it tries to assign the student to her second choice. If full, to the third choice and so on. Once this student has been assigned to a school, the algorithm moves on to the next person.

Under the deferred acceptance assignment, when the number of choices is constrained (1996 and after), students may have an incentive to exclude some desirable schools from their list if the probability of admission is too low (Haeringer and Klijn 2009). However, among the set of schools listed, it is a dominant strategy to list them in order of true preference (Chade and Smith 2006, Agarwal and Somaini 2018). Accordingly, so long as parents make rational choices, one can infer that a higher-ranked school is preferred to a lower-ranked school. We examine choices in Appendix C. Parents almost always rank more-selective schools higher. We show that is because (a) students rank schools very similarly, and (b) the highest-achieving students are admitted to their top choices first. As such, a preferred school is virtually synonymous with being more selective or more elite.

Secondary school begins in first form (the equivalent of 7 th grade) and ends at fifth form (the equivalent of 11th grade) when students take the Caribbean Secondary Education Certification (CSEC) examinations. These are equivalent to the British Ordinary levels examinations and are externally graded by the Caribbean Examinations Council (CXC). The CSEC examinations are given in 33 subjects. Passing five subjects (including English and mathematics) is a sufficient entry requirement for community colleges, technical schools, or training schools. It can also be used for entry at some colleges in the United States. Students who complete these requirements continue their studies at a tertiary institution (if accepted) or pursue the Caribbean Advanced Proficiency Examination (CAPE), also externally graded by CXC.

The CAPE is a tertiary-level program. Students seeking to attend University (as opposed to a community college) will take the CAPE. The CAPE is equivalent to the British Advanced levels examinations. The CAPE is a two-year program and includes two core units (Caribbean Studies and Communication Studies) and six other units. Passing at least two CAPE units is typically required

\footnotetext{
${ }^{5}$ The list of ranked schools is submitted before taking the BSSEE .
} 
for entry to the University of the West Indies. Passing six CAPE units is a common admission requirement to British higher education institutions. The post-secondary qualification of a CAPE Associate's Degree is awarded for passing seven CAPE units, including Caribbean Studies and Communication Studies.

\section{Data}

Our analytic sample is the full population of students who applied to a public secondary school in Barbados between 1987 and 2011. ${ }^{6}$ We obtained the official administrative BSSEE data for each of these years. These data include each student's name, date of birth, gender, primary school attended, parish of residence, total score on the BSSEE exam, the ranked list of secondary schools the student wished to attend, and the administrative assignment by the METI.

Administrative Examination Data: To track secondary performance, we collected data on the CSEC examinations (taken five years after secondary school entry, around age 16). The CSEC data are available for all years between 1993 and 2016. The CSEC data were linked to the 1987 through 2011 BSSEE cohorts by full name (first, middle, and last), gender, and date of birth. ${ }^{7}$ To track $^{2}$ post-secondary outcomes, we collected population data from the CAPE examinations (completed after two years of post-secondary studies, around age 18). The CAPE data are available for years 2005 through 2016, and are linked to the 1998 through 2009 BSSEE cohorts by name, gender, and date of birth. ${ }^{8}$ Both the CSEC and CAPE data contain scores for each subject examination taken.

Survey Data: Our longer-run outcomes come from the 2016 Barbados Survey of Living Conditions. This survey is a large, parish level representative two-percent survey of the population. It included data on 7,098 individuals collected between February 2016 and January 2017. It includes data on demographics, education, health, fertility, migration, consumption, employment, and income. ${ }^{9}$ The survey collected full names at age 10 (to account for name changes), date of birth, and gender so that it could be matched with the administrative BSSEE data. We matched 90 percent of surveyed individuals within the target BSSEE cohorts (aged 25-40 when surveyed). We show that our survey results likely generalize to the full population. First, the distributions of covariates and outcomes are similar in the administrative and survey samples (Appendix Table A1). Second, admission to a preferred school is unrelated to responding the survey and subsequently being matched with the BSSEE (Section V.1). Finally, the impacts on CSEC performance are similar in both the full administrative dataset and among those who are linked to the survey (Appendix Table A2).

\footnotetext{
${ }^{6}$ Around 91 percent of secondary students in Barbados are enrolled in the public education system.

${ }^{7}$ We matched 90 percent of individuals observed in the CSEC administrative records to the BSSEE records. The 10 percent rate of unmatched individuals closely mimics the 9 percent enrollment rate in private secondary schools who would not have taken the BSSEE.

${ }^{8}$ We matched 96 percent of individuals observed in the CAPE administrative records to the BSSEE records.

${ }^{9}$ The response rate of the survey was 80 percent, which is higher than the average for similar surveys in Latin America and the Caribbean.
} 


\section{III.1 Summary Statistics}

Table 1 presents summary statistics. The population is roughly half female and the average admitted school-cohort size is 157 students. About 68 percent of students took at least one CSEC subject, and 26.8 percent passed five subjects including English language and mathematics (i.e. qualified for tertiary education). ${ }^{10}$ We also break up the sample by the rank of the student's assigned school (based on the average incoming BSSEE scores). Among those assigned to the top ranked schools, incoming BSSEE scores are roughly one standard deviation higher than the average of the population (column 2). ${ }^{11}$ Unsurprisingly, students at these schools have much better outcomes than average. Indeed 62 percent of students at the most selective schools qualify for a tertiary education (column 2), while only 4.1 percent of students at the least selective schools do (column 4). In terms of post-secondary education, 40.6 percent of students at the most selective schools took at least one CAPE unit and 23.4 percent earned an Associate's degree. Almost no students at the least selective schools take the CAPE.

The lower panel of Table 1 presents summary statistics for individuals ages 25 to 40 who are matched to the surveys. Students at more selective schools have more years of education, are more likely to be employed in a managerial or professional position, and earn higher wages. Also, individuals at the most selective schools rely more on their school network when seeking employment. Only 1.9 percent of women assigned to the most selective schools had a live birth before age 18, while 16.4 percent of women in the bottom third of schools did. Preventive health behaviors (having medical insurance, dental checkups, gym attendance) are also more prevalent among individuals assigned to more selective schools. In our analyses, to reduce multiple inference problems we compute the following standardized summary indexes: educational attainment (combines years of education and university completion); labor market (combines being employed, working in a managerial or professional role, and the monthly wage); health (combines having medical insurance, attending yearly dental checkups, attending a gym at least once per week, and being within a normal Body Mass Index range). ${ }^{12}$ We also compute a long-term index which combines all these individual outcomes. ${ }^{13}$

\footnotetext{
${ }^{10}$ Because CSEC taking is not mandatory, this measure is not equivalent to secondary school completion. Students receive a School Leaving Certificate regardless of CSEC taking after completing five years of secondary school. About 87.5 percent of surveyed individuals in our reference BSSEE cohorts report having completed secondary school.

${ }^{11}$ The gender imbalance across the school ranks reflects the fact that there is one all-girls school in the middle-ranked schools, and one all-boys school in the bottom-ranked schools.

${ }^{12}$ Persons are classified within normal weight if they have a BMI below 25 but on or above of 18.5.

${ }^{13}$ Following Kling et al. (2007), we first standardize each index component. The summary indexes are the geometric means of the standardized non-missing components for each individual.
} 


\section{Empirical Strategy}

The assignment mechanism described in Section II creates a test score cutoff above which applicants to each school are admitted and below which they are not. If nothing else differs for those scoring just above and below the cutoff, any sudden change in outcomes as students' BSSEE score goes from below to above the cutoff for a preferred school can be attributed to attending that preferred school (Hahn et al. 2001). We exploit the discontinuity in the admission probability through the cutoff by estimating the following two-stage least-squares (2SLS) model:

$$
\begin{gathered}
\text { Attend }_{i j t}=\pi \cdot \text { Above }_{i j t}+f_{1}\left(\text { BSEE }_{i t}\right)+X_{i j t} \gamma_{1}+C_{1, j t}+P_{1, i j t}+\varepsilon_{1, i j t} \\
Y_{i j t}=\beta \cdot \text { Attend }_{i j t}+f_{2}\left(B S E E_{i t}\right)+X_{i j t} \gamma_{2}+C_{2, j t}+P_{2, i j t}+\varepsilon_{2, i j t}
\end{gathered}
$$

In the first stage equation (1) we predict whether individual $i$ attends school $j$ at time $t$, Attend $_{i j t}$, as a function of scoring above the cutoff for preferred school $j$ at time $t$, Above $_{i j t}$, and controls. To account for latent outcomes that vary smoothly through the cutoffs, we control for a cubic in BSSEE and a cubic of BSSEE interacted with the $A b o v e_{i j t}$ indicator $\left(f_{1}\left(B S E E_{i t}\right)\right)$. We also include parish of residency fixed effects and gender (included in $X_{i j t}$ ). Following Jackson (2010) and PopEleches and Urquiola (2013), we stack the data across all application pools into a single cutoff, recenter BSSEE scores at each respective cutoff, and include cutoff fixed effects $\left(C_{1, j t}\right)$. The cutoff fixed effects ensure that all comparisons are among students who applied to the same school in the same year. In the second stage (equation 2), the outcome of interest $\left(Y_{i j t}\right)$ is a function of predicted preferred school attendance (from the first stage) and all controls from equation (1). The second stage excluded instrument is Above $_{i j t}$. Because the same individual can enter the data for multiple cutoffs, the estimated standard errors are clustered at the student level. ${ }^{14}$

Student's ranked choices reflect student preferences and are much stronger predictors of student outcomes than variables typically observed in most datasets. We add choice-group fixed effects $\left(P_{1, j t}\right)$ as controls to increase precision. These choice group fixed effects define the unique set of schools in a student's list along with the unique ranking of those schools. As such, students in the same choice group list the same set of schools in the exact same order. All of our results are robust to excluding these controls.

The identifying assumption behind this Regression-Discontinuity-based model is that nothing other than the change in admission probability changes in a discontinuous manner through the cut-

\footnotetext{
${ }^{14}$ In our context, this approach is equivalent to heteroskedasticity-robust estimated standard errors allowing for offdiagonal non-zero terms in the variance-covariance matrix when the same individual enters the data for more than one cutoff. Kolesár and Rothe (2018) show this to be a more conservative approach than also clustering estimated standard errors at the level of the running variable. Indeed, our results are more conservative with the adopted approach than if we also cluster standard errors at the BSSEE relative score level.
} 
off. We test this assumption in several ways. Following McCrary (2008), we test for a discontinuity in density through the cutoff and find no change in density either in the full population or in the survey sample (Table 2, panel A). As an additional test for smoothness through the cutoff, we estimate reduced form models on each of our predetermined covariates. None of the 32 covariates is related (at the 5 percent level) to scoring above the cutoff in either the full population or the survey sample (Appendix Table A3). To summarize impacts on all these covariates into a more efficient test, we create predicted CSEC certification, CAPE Associate's degree, and long run-index variables (based on all covariates). ${ }^{15}$ None of these predicted outcomes is related to scoring above the cutoff (Table 2, panel B). All these tests suggest that our estimation strategy is likely valid.

\section{Results}

\section{V.1 The First Stage and Survey Representativeness}

Table 2, panel C presents the first stage estimates on the Above $e_{i j t}$ indicator from equation (1). For observations within $0.75 \mathrm{SD}$ of the cutoff, in the population, scoring above a cutoff increases the likelihood of attending a preferred school by 74.5 percentage points. ${ }^{16}$ The top left panel of Figure 2 shows clear visual evidence of a discontinuous jump in the probability of attending a preferred school through the cutoff. Table 2, panel D shows that attending a preferred school increases peer quality (average BSSEE scores) by 0.25 standard deviations, and also decreases heterogeneity in peer quality with lower cohort sizes. While there are peer quality differences across schools, all secondary schools teach a homogeneous national curriculum approved by the METI. Also, because public secondary schools are allocated funding annually by the METI, per-pupil school resources are essentially the same across all schools. As such, any differences in outcomes are not due to differences in school resources or curriculum across schools.

To provide further evidence that our survey results are likely representative of the population, we show that the first stage is identical in the survey sample (Panel C, columns 3 and 4). ${ }^{17}$ We also show no change in the likelihood of being matched to and then responding to the survey through the cutoffs (panel E). Consistent with this, the estimated effects on school environments are statistically indistinguishable between the population and the survey sample (Panel D, column 5). This all lends even greater credibility to the survey results generalizing to the full population.

\section{V.2 Effects on Secondary School Academic Achievement}

Table 3, panel A presents estimated impacts on CSEC performance (age 16) measured at the

\footnotetext{
${ }^{15}$ We report impacts on all predicted outcomes across different samples by gender in Appendix Table A4.

${ }^{16}$ Individuals can appear for multiple cutoffs in the stacked data. As such, regression models have more observations than individuals.

${ }^{17}$ To improve precision, results from the survey sample exploit all observations. However, we show that these are robust to alternative bandwidth restrictions (Appendix Figure A1).
} 
end of secondary school. To use the same cohorts for which CAPE data (age 18+) are available, we focus on the BSSEE cohorts from 1998 to $2009 .{ }^{18}$ We present estimated preferred school impacts in models that do not include the choice group effects (column 1). The results with and without these controls are very similar, so we focus on the full model with all controls.

Students who attend preferred schools do not perform better on the secondary school leaving exams, and may do slightly worse. Overall (column 2), we find no effect on taking the CSEC exams, and small marginally significant negative effect on the likelihood of qualifying for tertiary education. ${ }^{19}$ This pattern is the same for both men and women (columns 3 and 4). The lack of improved CSEC outcomes through the cutoff are presented visually in the top right panel of Figure 2. These findings echo the several studies documenting zero effects on test scores from attending more selective schools (see Figure 1) and possible negative effects on school completion in Dustan et al. (2017). ${ }^{20}$

Most studies in this literature use regression discontinuity designs that estimate school impacts for the marginal applicant (who just made or missed the cutoff). As such, one potential explanation for the null effects is that marginal applicants don't benefit from preferred schools even if average students do. We implement a formal test of this (see Appendix D) and find that the effects are the same, on average, for the marginal applicant and the average attendee - so that this does not explain for the null impacts for highly-demanded schools.

\section{V.3 Effects on Post-Secondary Certification}

To explore whether improved longer-run impacts can explain strong demand for schools with no short-run test-score impacts, we now examine post-secondary outcomes. We examine CAPE taking (a measure of continued education beyond secondary school) and earning a CAPE Associate's degree in panel B of Table 3. Overall, columns 1 and 2 show that attending a preferred school increases the likelihood of taking the CAPE by about 2 percentage points and increases the likelihood of earning an Associate's degree by 2.1 percentage points ( $p$-value $<0.01$ ). That is, despite a slight reduction in the likelihood of passing the secondary school exam, students at preferred schools are more likely to enter and complete the CAPE post-secondary education. There is little evidence of any differential effect by gender. The corresponding visual evidence of a discontinuous jump in earning an Associate's degree through the cutoff is in the lower left panel of Figure 2.

The contrast between the slight negative impacts on short run test scores (age 16) and postsecondary educational attainment (age 18) for the same population is compelling evidence that a

\footnotetext{
${ }^{18}$ Appendix Table A2, panel A shows estimated CSEC effects using the BSSEE cohorts 1987-2002 (25-40 years old when surveyed) in whom we focus to estimate longer-term effects later. Results are similar.

${ }^{19}$ Estimated impacts on other CSEC outcomes are in Appendix Table A5.

${ }^{20}$ Appendix Table A2, panel B shows estimated effects on the same outcomes but restricting the sample to individuals that were matched with the survey data. Results are similar suggesting null effects.
} 
lack of short-run test score impacts does not imply a lack of impact on overall longer-run wellbeing. The estimated positive effect on CAPE taking of 2 percentage points is equivalent to 13.16 percent of the sample average, and almost double the average at the least preferred (selective) schools. This pattern of improved longer run outcomes for preferred schools is echoed in the survey data examined in the next section. ${ }^{21}$

\section{V.4 Effects on Long-Run Outcomes}

To summarize the longer-run survey outcomes (between ages 25 and 40), we examine impacts on the long-run index (which combines education, labor market, and health outcomes). The lower right panel of Figure 2 shows a clear jump in the long-run index through the cutoff - indicating that attending a preferred school improved students long run well-being. To provide statistical evidence that this jump is real, we randomly assigned "placebo" cutoffs to each school-cohort and estimated the cutoff effect across 2000 replications. None of the placebo effects is as large as the real one (see Appendix Figure A2). The 2SLS estimates in panel C of Table 3 show that overall, attending a preferred school increases the long-term index by 0.187 standard deviations ( $p$ value $<0.01$ ). Despite no significant impacts on short-run test scores, attending a preferred school has large positive, statistically significant, impacts on overall long-term well-being. While the point estimates are positive for both females and males (columns 3 and 4), one cannot reject that the effect for males is zero. However, one can reject equality of impacts by gender at the 10 percent level. We now explore impacts on particular components of long-run well-being.

\section{V.4.1 Educational Attainment}

Given that many individuals pursue university studies after the CAPE (for which we find positive impacts), one might expect to see increases in overall educational attainment. Panel $\mathrm{C}$ of Table 3 shows that attending a preferred school increases the educational attainment index only for women. Women who attend a preferred school have 0.376 standard deviations ( $p$-value $<0.01$ ) higher educational attainment index (column 3 ), while the estimate is negative and not significant for men (column 4). This positive effect for women is driven by positive effects on each of the individual components of the index (Appendix Table A6). For women, attending a preferred school increases the likelihood of having a university degree by 17 percentage points, and increases the years of education attained by 1.64 years. Given that both male and female students who attend preferred schools experienced increased CAPE completion, the lack of an overall educational effect for men is surprising. We explore mechanisms behind this asymmetric result in Section V.6.

\footnotetext{
${ }^{21}$ Appendix Table A2, panel C shows estimated CAPE effects for the cohorts that overlap with the longer-term sample (i.e. BSSEE cohorts 1998-2002). While less precise, the results are similar.
} 


\section{V.4.2 Labor Market Outcomes}

Similar to the estimated effects on educational attainment, panel C of Table 3 shows that attending a more selective school increases labor market success only for women. For women, preferred school attendance has a positive effect on the labor market index of 0.389 standard deviations $(p$ value $<0.01$ ) (column 3 ). However, there is no economically or statistically significant effect for men (column 4). This positive effect for women is driven by significantly positive effects on each of the components of the index (Appendix Table A6). For women, attending a preferred school increases the likelihood of being employed by 13 percentage points, increases the likelihood of holding a managerial job by 24 percentage points, and increases log monthly wages by 41 points. For both women and men, attending a preferred school is associated with increased labor market employment, but this effect is larger for women and not significant for men. These results are consistent with a standard human capital model (e.g. Becker 1975) where the increased educational attainment associated with attending a preferred school among women (but not men) being rewarded in the labor market for women (but not men). The fact that we observe no appreciable labor market effects for men (for whom there was no increase in overall educational attainment) suggests that the labor market benefits for women are not driven by more elite schools signaling ability (e.g. Spence 1973; MacLeod and Urquiola 2015)

\section{V.4.3 Adult Health}

One key innovation of this paper is to estimate causal impacts of schools on health. Panel $\mathrm{C}$ of Table 3 shows that attending a preferred school increases the health index by 0.22 standard deviations ( $p$-value $<0.01$ ). This health effect is similar for both women and men. Estimated effects on the individual components of the health index are shown in Appendix Table A7. Selective school attendance increased the likelihood of being within a normal BMI range by 16.7 percentage points and reduced the likelihood of being overweight or obese. Consistent with preferred schools leading to better practices that improve health status, attending a preferred school increases the likelihood of attending a gym at least once per week by 12.5 percentage points, and increases the likelihood of having an annual dental checkup by 11 percentage points. Interestingly, there is no statistically significant impact on having medical insurance- suggesting that health status improvements are largely due to improved behavioral norms at more preferred schools. Even though there were only detectable educational and employment benefits for women, long-term health improved for both women and men because of selective school attendance. This finding constitutes a previously undocumented benefit to preferred school attendance.

\section{V.5 Robustness}

To assuage concerns that our results are driven by modelling choices, we show that our 2SLS estimates for each outcome are similar for any choice of bandwidth (Appendix Figure A1). Also, 
Appendix Table A8 shows the robustness of our estimates to alternative BSSEE polynomial specifications. We also show robustness to two-way clustered standard errors at the individual and BSSEE scores levels (Appendix Table A9).

\section{V.6 Exploration of Potential Mechanisms}

A possible explanation for the lack of increased male earnings at preferred schools is that preferred schools led males to pursue more academic oriented programs at the expense of pursuing technical and vocational training. ${ }^{22}$ If technical/vocational training had a higher rate of return than academic programs for these marginal males, the labor market impacts could be negative. Our data do not support this hypothesis. We find no reduction in having a technical/vocation credential for males (panel D of Table 3).

One possible labor market benefit to attending a preferred school is access to better-connected social networks that can be leveraged to improve employment opportunities (Schmutte, 2015). Indeed, the likelihood of having been referred to one's current job by somebody in one's secondary school network increases by 3.7 percentage points due to attending a preferred school (panel E of Table 3). The referral effect is similar for women and men. Although only women experienced positive effects on the labor market index, the fact that both men and women experienced similar increases in the likelihood of employment (see panel B of Appendix Table A6) suggests that improved referral networks may be a mechanism. In contrast, men have no wage increases while women do, suggesting that referrals do not explain the higher wages for women. The results are consistent with the referral effect leading to increased employment, and the increased educational attainment (for women) increasing wages (for women) conditional on being employed. We examine the education mechanism further below.

Attending a preferred school increased Associate's degree receipt for both women and men, but educational attainment only increased for women. One explanation for these findings is that the gains in educational attainment for men who pass the CAPE were offset by losses among those who do not take the secondary school exam. Indeed, the reduction in qualifying for tertiary education (based on CSEC performance) and earning a CAPE Associate's degree are opposite in sign and almost identical in magnitude. However, the differences in overall educational attainment between men and women imply that women who completed the CAPE were more likely than men to continue their studies and pursue a university degree.

The notion that school quality may increase educational attainment for girls more than for boys is not new (e.g. Jackson 2010; Deming et al. 2014; Clark 2010). However, the reasons for the gender differences are not well understood. One potential explanation is that attending a better school reduces the likelihood of teen pregnancy (which disproportionately impacts girls). Given

\footnotetext{
${ }^{22}$ This was proposed in Clark and Del Bono (2016). However, they are unable to test this hypothesis in their data.
} 
that teen motherhood has been shown, by some, to adversely impact educational attainment and earnings (e.g. Fletcher and Wolfe 2009), this could explain the pattern of results. Panel F of Table 3 shows that the likelihood of giving birth by age 18 is reduced by 6.2 percentage points ( $p$-value $<0.05)$. Relative to the average in the population, this represents a considerable 59 percent decrease. We find no impact, however, on total fertility (Appendix Table A10) - indicating that preferred schools lead to delayed child bearing rather than reduced fertility. This is suggestive evidence that decreased teen motherhood may have played an important role in explaining the long-term improvements in educational attainment and labor market outcomes for women.

\section{Conclusions}

Our meta-analysis reveals that, across several national contexts, the average impact of attending a preferred public school on test scores is not distinguishable from zero. Using data from Barbados, we replicate this result. We argue that these findings can be rationalized by parents valuing school impacts on a broader set of outcomes than those measured by achievement tests. Our analysis of long-run outcomes support this explanation. Attending a preferred school led to sizable improvements in educational attainment, labor market success, and health. The long-run impacts are larger for girls, who also experience lower teen pregnancy. Given these patterns, if parents care about these outcomes, it may be reasonable for them to prefer these schools despite no test-score improvements in the short-run.

The fact that we find no impact of attending preferred schools on short-run test scores, but do find sizable impacts on longer-run outcomes is important. Our results suggest that test score impacts may not be the best measure of a school's impacts on longer-run outcomes (Jackson 2018; Heckman et al. 2006). Accordingly, policymakers should be cautious regarding using test score impacts in accountability systems and incentive-pay schemes. Moreover, these results underscore the need for evaluations of school choice programs and private voucher programs to move beyond test score impacts alone, and to examine broader sets of outcomes that parents may value. 


\section{References}

Daniel Aaronson, Bhashkar Mazumder, Seth G. Sanders, and Evan J. Taylor. Estimating the Effect of School Quality on Mortality in the Presence of Migration: Evidence from the Jim Crow South. SSRN Electronic Journal, 9 2017. ISSN 1556-5068. doi: 10.2139/ssrn.3045447.

Atila Abdulkadiroğlu, Parag A Pathak, and Alvin E Roth. The New York City High School Match. American Economic Review, 95(2):364-367, 4 2005. ISSN 0002-8282. doi: 10.1257/ 000282805774670167.

Atila Abdulkadiroğlu, Joshua Angrist, and Parag Pathak. The Elite Illusion: Achievement Effects at Boston and New York Exam Schools. Econometrica, 82(1):137-196, 1 2014. ISSN 0012-9682. doi: 10.3982/ECTA10266.

Atila Abdulkadiroglu, Joshua D. Angrist, Yusuke Narita, Parag A. Pathak, and Roman A. Zarate. Regression Discontinuity in Serial Dictatorship: Achievement Effects at Chicago's Exam Schools. American Economic Review, 107(5):240-45, 2017. doi: 10.1257/aer.p20171111.

Nikhil Agarwal and Paulo Somaini. Demand Analysis Using Strategic Reports: An Application to a School Choice Mechanism. Econometrica, 86(2):391-444, mar 2018. ISSN 0012-9682. doi: 10.3982/ECTA13615. URL https://www.econometricsociety.org/doi/10.3982/ ECTA13615.

Kehinde F Ajayi. Student Performance and the Effects of Academic versus Nonacademic School Attributes. 2015.

Kathryn Anderson, Xue Gong, Kai Hong, and Xi Zhang. Do selective high schools improve student achievement? Effects of exam schools in China. China Economic Review, 40:121134, sep 2016. ISSN 1043-951X. doi: 10.1016/J.CHIECO.2016.06.002. URL https: //wWw.sciencedirect.com/science/article/pii/S1043951X16300645.

Christopher N. Avery, Mark E. Glickman, Caroline M. Hoxby, and Andrew Metrick. A Revealed Preference Ranking of U.S. Colleges and Universities *. The Quarterly Journal of Economics, 128(1):425-467, 2 2013. ISSN 0033-5533. doi: 10.1093/qje/qjs043.

Lisa Barrow Barrow, Lauren Sartain, and Marisa de la Torre. The Role of Selective High Schools in Equalizing Educational Outcomes: Using Place-Based Affirmative Action to Estimate Heterogeneous Effects by Neighborhood Socioeconomic Status (Revised September 2017) - Federal Reserve Bank of Chicago. 2017. URL https://www.chicagofed.org/publications/ working-papers/2016/wp2016-17.

Gary S Becker. Chapter Title: Front matter, Human Capital: A Theoretical and Empirical Analysis, with Special Reference to Education. 1975.

S. E. Black. Do Better Schools Matter? Parental Valuation of Elementary Education. The 
Quarterly Journal of Economics, 114(2):577-599, 5 1999. ISSN 0033-5533. doi: 10.1162/ 003355399556070.

Michael Borenstein, Larry Hedges, Julian Higgins, and Hannay Rothstein. Introduction to Meta-Analysis. John Wiley and Sons, Ltd, 2009. ISBN 9780470057247. doi: 10.1002/ 9780470743386.

Kasey Buckles, Andreas Hagemann, Ofer Malamud, Melinda Morrill, and Abigail Wozniak. The effect of college education on mortality. Journal of Health Economics, 50:99-114, 122016. ISSN 0167-6296. doi: 10.1016/J.JHEALECO.2016.08.002.

Sa A. Bui, Steven G. Craig, and Scott A. Imberman. Is Gifted Education a Bright Idea? Assessing the Impact of Gifted and Talented Programs on Students. American Economic Journal: Economic Policy, 6(3):30-62, 8 2014. ISSN 1945-7731. doi: 10.1257/pol.6.3.30.

Simon Burgess, Ellen Greaves, Anna Vignoles, and Deborah Wilson. What Parents Want: School Preferences and School Choice. The Economic Journal, 125(587):1262-1289, 9 2015. ISSN 00130133. doi: 10.1111/ecoj.12153.

Hector Chade and Lones Smith. Simultaneous Search. Econometrica, 74(5):1293-1307, 92006. ISSN 0012-9682. doi: 10.1111/j.1468-0262.2006.00705.x.

Damon Clark. Selective Schools and Academic Achievement. The B.E. Journal of Economic Analysis \& Policy, 10(1):1-40, 2010.

Damon Clark and Emilia Del Bono. The Long-Run Effects of Attending an Elite School: Evidence from the United Kingdom. American Economic Journal: Applied Economics, 8(1):150-176, 1 2016. ISSN 1945-7782. doi: 10.1257/app.20130505.

Damon Clark and Heather Royer. The Effect of Education on Adult Mortality and Health: Evidence from Britain. American Economic Review, 103(6):2087-2120, 10 2013. ISSN 0002-8282. doi: 10.1257/aer.103.6.2087.

Julie Berry Cullen, Brian A Jacob, and Steven Levitt. The Effect of School Choice on Participants: Evidence from Randomized Lotteries. Econometrica, 74(5):1191-1230, 9 2006. ISSN 00129682. doi: 10.1111/j.1468-0262.2006.00702.x.

David Cutler and Adriana Lleras-Muney. Education and Health: Evaluating Theories and Evidence. Technical report, National Bureau of Economic Research, Cambridge, MA, 72006.

Thomas Dee and Xiaohuan Lan. The achievement and course-taking effects of magnet schools: Regression-discontinuity evidence from urban China. Economics of Education Review, 47:128142, 2015.

David J. Deming. Better Schools, Less Crime? *. The Quarterly Journal of Economics, 126(4): 2063-2115, 11 2011. ISSN 0033-5533. doi: 10.1093/qje/qjr036. 
David J. Deming. Using School Choice Lotteries to Test Measures of School Effectiveness. American Economic Review, 104(5):406-411, 5 2014. ISSN 0002-8282. doi: 10.1257/aer.104.5.406.

David J. Deming, Justine S. Hastings, Thomas J. Kane, and Douglas O. Staiger. School Choice, School Quality, and Postsecondary Attainment, 2014.

Andrew Dustan, Alain de Janvry, and Elisabeth Sadoulet. Flourish or Fail? Journal of Human Resources, 52(3):756-799, 7 2017. ISSN 0022-166X. doi: 10.3368/jhr.52.3.0215-6974R1.

Jason M. Fletcher and Barbara L. Wolfe. Education and Labor Market Consequences of Teenage Childbearing: Evidence Using the Timing of Pregnancy Outcomes and Community Fixed Effects. Journal of Human Resources, 44(2), 2009.

David Frisvold and Ezra Golberstein. School quality and the education-health relationship: Evidence from Blacks in segregated schools. Journal of Health Economics, 30(6):1232-1245, 12 2011. ISSN 01676296. doi: 10.1016/j.jhealeco.2011.08.003.

D. Gale and LS Shapley. College Admissions and the Stabilty of Marriage. The American Mathematical Monthly, 69(1):9-15, 1 1962. ISSN 00029890. doi: 10.2307/2312726.

Guillaume Haeringer and Flip Klijn. Constrained school choice. Journal of Economic Theory, 144 (5):1921-1947, 9 2009. ISSN 0022-0531. doi: 10.1016/J.JET.2009.05.002.

Jinyong Hahn, Petra Todd, and Wilbert Klaauw. Identification and Estimation of Treatment Effects with a Regression-Discontinuity Design. Econometrica, 69(1):201-209, 1 2001. ISSN 00129682. doi: 10.1111/1468-0262.00183.

Justine Hastings, Thomas Kane, and Douglas Staiger. Preferences and Heterogeneous Treatment Effects in a Public School Choice Lottery. 4 2006. doi: 10.3386/w12145.

Justine Hastings, Christopher Neilson, and Seth Zimmerman. The Effects of Earnings Disclosure on College Enrollment Decisions. NBER Working Paper, 6 2015. doi: 10.3386/w21300.

Justine S Hastings, Thomas J Kane, and Douglas O Staiger. Heterogeneous Preferences and the Efficacy of Public School Choice. Working Paper, 2009.

James J. Heckman, Jora Stixrud, and Sergio Urzua. The Effects of Cognitive and Noncognitive Abilities on Labor Market Outcomes and Social Behavior. Journal of Labor Economics, 24(3): 411-482, 7 2006. ISSN 0734-306X. doi: 10.1086/504455.

Mark Hoekstra, Pierre Mouganie, and Yaojing Wang. Peer Quality and the Academic Benefits to Attending Better Schools. Journal of Labor Economics, 36(4):841-884, oct 2018. ISSN 0734306X. doi: 10.1086/697465. URL https://www. journals uchicago.edu/doi/10.1086/ 697465.

C. Kirabo Jackson. Do Students Benefit from Attending Better Schools? Evidence from Rule-based 
Student Assignments in Trinidad and Tobago*. The Economic Journal, 120(549):1399-1429, 12 2010. ISSN 00130133. doi: 10.1111/j.1468-0297.2010.02371.x.

C. Kirabo Jackson. What Do Test Scores Miss? The Importance of Teacher Effects on Non-Test Score Outcomes. Journal of Political Economy, 5 2018. doi: 10.3386/w22226.

Andrew M Jones, Nigel Rice, and Pedro Rosa Dias. Long-Term Effects of School Quality on Health and Lifestyle: Evidence from Comprehensive Schooling Reforms in England. Source: Journal of Human Capital, 5(3):342-376, 2011. doi: 10.1086/662441.

Jeffrey R Kling, Jeffrey B Liebman, and Lawrence F Katz. Experimental Analysis of Neighborhood Effects. Econometrica, 75(1):83-119, 1 2007. ISSN 0012-9682. doi: 10.1111/j.1468-0262.2007. 00733.x. URL http://doi.wiley.com/10.1111/j.1468-0262.2007.00733.x.

Michal Kolesár and Christoph Rothe. Inference in Regression Discontinuity Designs with a Discrete Running Variable. American Economic Review, 108(8):2277-2304, 8 2018. ISSN 00028282. doi: 10.1257/aer.20160945. URL https://pubs.aeaweb.org/doi/10.1257/aer. 20160945.

Adrienne M. Lucas and Isaac M. Mbiti. Effects of School Quality on Student Achievement: Discontinuity Evidence from Kenya. American Economic Journal: Applied Economics, 6(3):234263, 7 2014. ISSN 1945-7782. doi: 10.1257/app.6.3.234.

W. Bentley MacLeod and Miguel Urquiola. Reputation and School Competition. American Economic Review, 105(11):3471-3488, 11 2015. ISSN 0002-8282. doi: 10.1257/aer.20130332.

Ofer Malamud, Andreea Mitrut, and Cristian Pop-Eleches. The Effect of Education on Mortality and Health: Evidence from a Schooling Expansion in Romania. Technical report, National Bureau of Economic Research, Cambridge, MA, 22018.

Justin McCrary. Manipulation of the running variable in the regression discontinuity design: A density test. Journal of Econometrics, 142(2):698-714, 2 2008. ISSN 0304-4076. doi: 10.1016/ J.JECONOM.2007.05.005.

Albert Park, Xinzheng Shi, Chang-tai Hsieh, and Xuehui An. Magnet high schools and academic performance in China: A regression discontinuity design. Journal of Comparative Economics, 43(4):825-843, nov 2015. ISSN 0147-5967. doi: 10.1016/J.JCE.2015.10.013. URL https: //wWw.sciencedirect.com/science/article/pii/S0147596715000979.

Cristian Pop-Eleches and Miguel Urquiola. Going to a Better School: Effects and Behavioral Responses. American Economic Review, 103(4):1289-1324, 6 2013. ISSN 0002-8282. doi: 10.1257/aer.103.4.1289.

Ian M. Schmutte. Job Referral Networks and the Determination of Earnings in Local Labor Markets. Journal of Labor Economics, 33(1):1-32, 1 2015. ISSN 0734-306X. doi: 10.1086/677389. 
Michael Spence. Job Market Signaling. The Quarterly Journal of Economics, 87(3):355, 81973. ISSN 00335533. doi: 10.2307/1882010. 
Figure 1. Effects of Preferred and Elite Public Secondary Schools on Test Scores

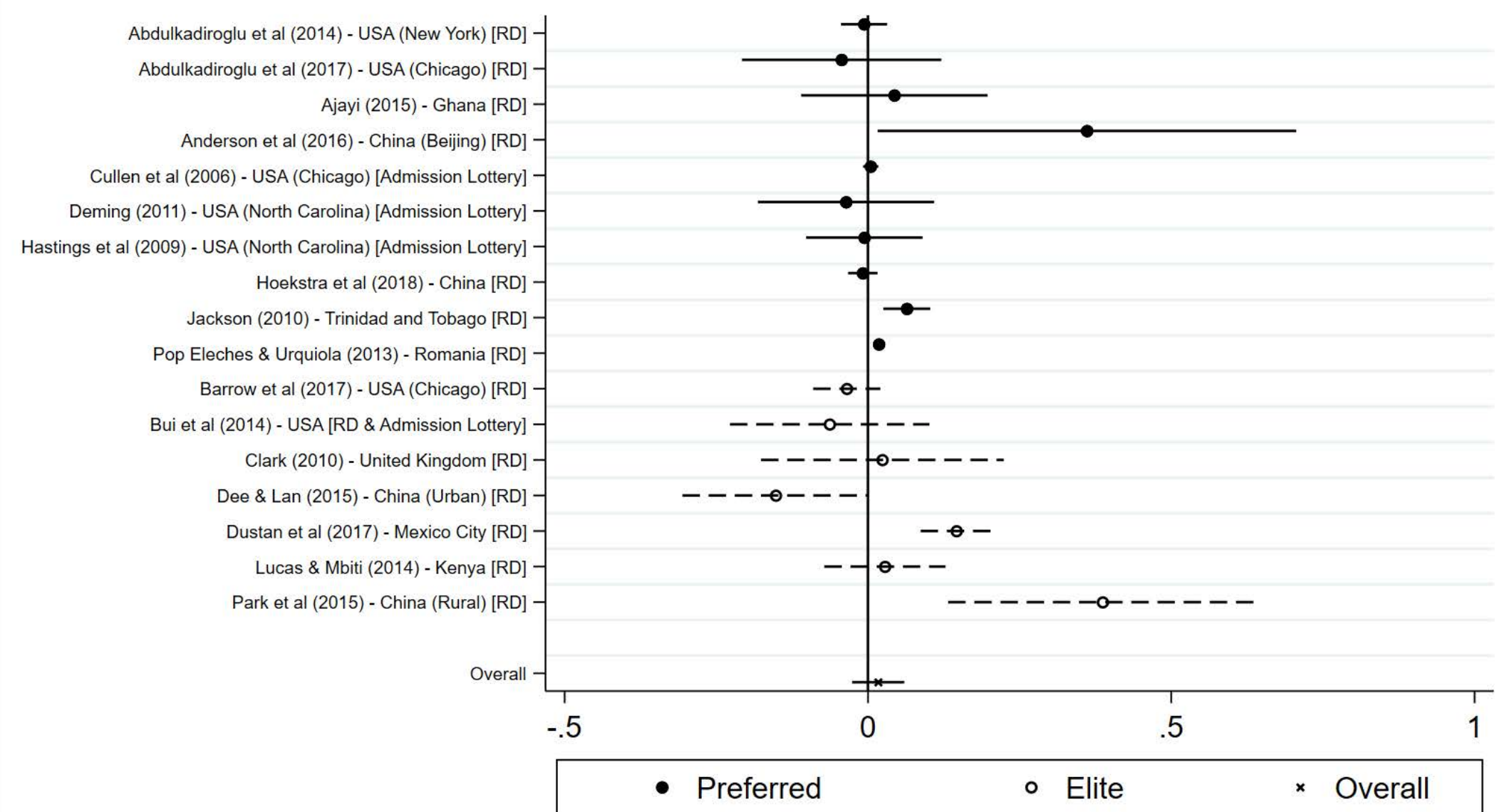

Notes: The individual standardized estimated effects along with their 95 percent confidence intervals are shown. RD denotes a regression discontinuity design exploiting admission scores cutoffs. Admission Lottery refers to identification strategies exploiting randomized admission lotteries for oversubscribed schools. The overall weighted average effect $(\mu)$ considers a weight $W_{j}=\left(S E_{j}^{2}+T^{2}\right)^{-1}$ for each study $j$. Where $S E_{j}^{2}$ is the variance of the estimated effect from each study $j$ and $T^{2}$ is the between-study variance (resulting from a random-effects meta-regression). The prediction interval of the overall weighted average effect is computed as $\mu \pm z \sqrt{T^{2}+S E^{2}}$. The prediction interval presents the expected range of true effects in similar studies. The resulting overall weighted average effect shown is $0.017 \mathrm{sd}$ with a 95 percent prediction interval of $[-0.026 ; 0.059]$. 
Figure 2. First Stage and RD Effects
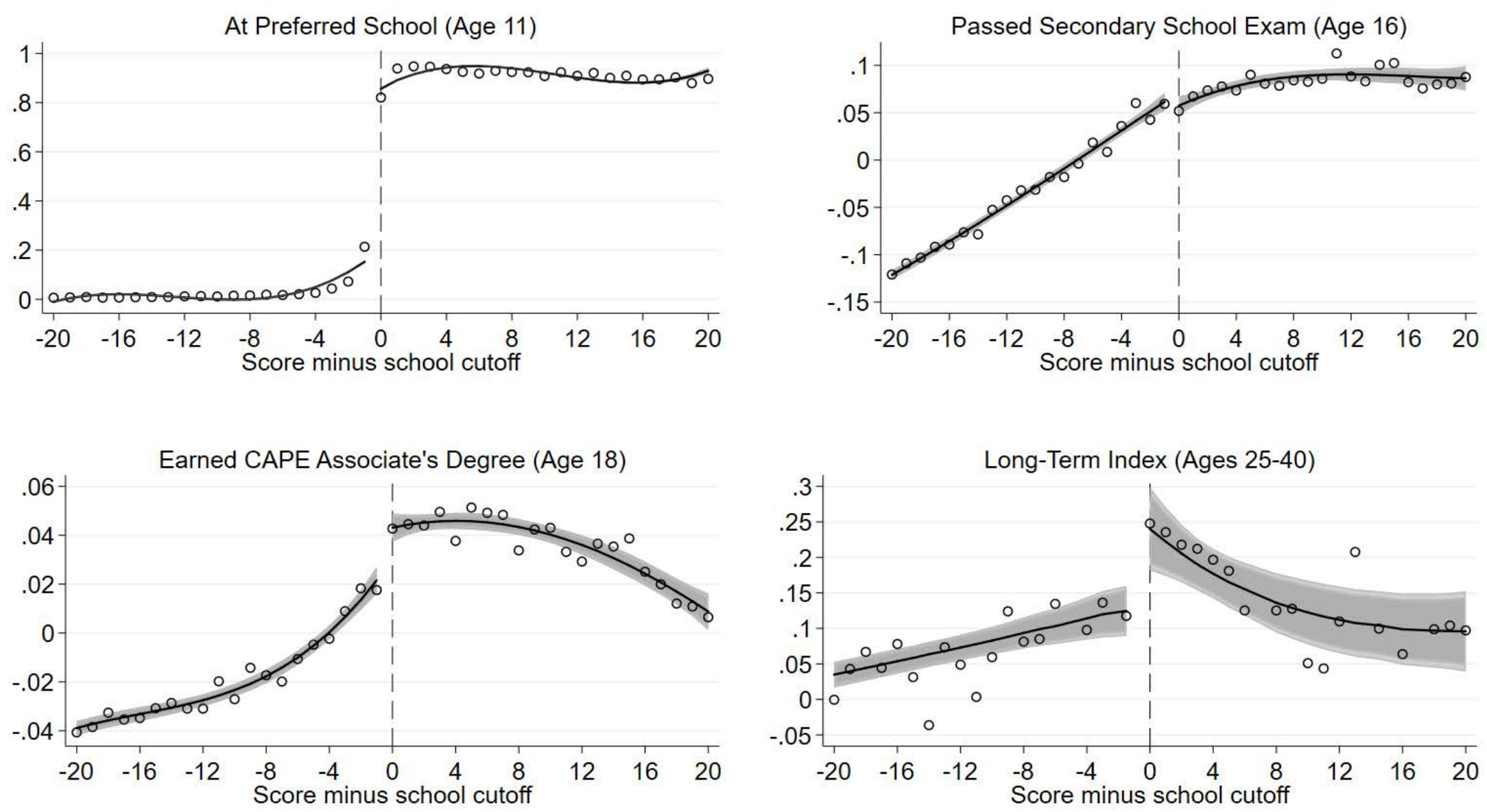

Notes: The X-axis is the BSSEE score relative to the cutoff. The upper-left panel plots the likelihood of actually attending a preferred school. The other panels plot residuals from regressing the outcome on cutoff and school preferences fixed effects. The circles are means corresponding to 1-point bins of the relative score. The solid lines are generated by fitting a third degree polynomial of the relative score fully interacted with the 'Above' indicator. The 90 (95) percent confidence interval of the fitted polynomial is presented in dark (light) gray. 


\section{Table 1: Summary Statistics}

\begin{tabular}{|c|c|c|c|c|}
\hline $\begin{array}{l}\text { School Rank Range (by average } \\
\text { incoming BSSEE scores): }\end{array}$ & $\frac{\text { All Schools }}{(1)}$ & $\begin{array}{c}1-8 \\
(2)\end{array}$ & $\frac{9-16}{(3)}$ & $\frac{17-24}{(4)}$ \\
\hline \multicolumn{5}{|c|}{ Panel A: Baseline Characteristics (prior to secondary school enrollment) } \\
\hline Standardized BSSEE score & $\begin{array}{c}0.000 \\
(1.000)\end{array}$ & $\begin{array}{c}1.107 \\
(0.416)\end{array}$ & $\begin{array}{c}0.076 \\
(0.468)\end{array}$ & $\begin{array}{c}-0.983 \\
(0.621)\end{array}$ \\
\hline Female & $\begin{array}{c}0.497 \\
(0.500)\end{array}$ & $\begin{array}{c}0.508 \\
(0.500)\end{array}$ & $\begin{array}{c}0.614 \\
(0.487)\end{array}$ & $\begin{array}{c}0.384 \\
(0.486)\end{array}$ \\
\hline Admitted cohort size & $\begin{array}{c}156.877 \\
(47.70)\end{array}$ & $\begin{array}{l}150.232 \\
(31.02)\end{array}$ & $\begin{array}{c}169.590 \\
(46.71)\end{array}$ & $\begin{array}{c}151.743 \\
(58.54)\end{array}$ \\
\hline \multicolumn{5}{|c|}{ Panel B: CSEC Performance (after 5 years of secondary school-age 16) } \\
\hline Took at least 1 subject & $\begin{array}{c}0.677 \\
(0.468)\end{array}$ & $\begin{array}{c}0.886 \\
(0.317)\end{array}$ & $\begin{array}{c}0.781 \\
(0.414)\end{array}$ & $\begin{array}{c}0.411 \\
(0.492)\end{array}$ \\
\hline Qualified for tertiary* & $\begin{array}{c}0.268 \\
(0.443)\end{array}$ & $\begin{array}{c}0.620 \\
(0.485)\end{array}$ & $\begin{array}{c}0.194 \\
(0.396)\end{array}$ & $\begin{array}{c}0.041 \\
(0.198)\end{array}$ \\
\hline Individuals & 95,391 & 29,145 & 31,035 & 35,211 \\
\hline \multicolumn{5}{|c|}{ Panel C: CAPE Performance (after 2 years of post-secondary studies - age 18) } \\
\hline Took at least 1 unit & $\begin{array}{c}0.152 \\
(0.359)\end{array}$ & $\begin{array}{c}0.406 \\
(0.491)\end{array}$ & $\begin{array}{c}0.061 \\
(0.239)\end{array}$ & $\begin{array}{c}0.010 \\
(0.102)\end{array}$ \\
\hline Earned Associate's Degree & $\begin{array}{c}0.080 \\
(0.272)\end{array}$ & $\begin{array}{c}0.234 \\
(0.423)\end{array}$ & $\begin{array}{c}0.017 \\
(0.130)\end{array}$ & $\begin{array}{c}0.003 \\
(0.056)\end{array}$ \\
\hline Individuals & 43,984 & 13,764 & 15,255 & 14,965 \\
\hline \multicolumn{5}{|c|}{ Panel D: Survey Sample BSSEE Cohorts 1987 - 2002 (25 - 40 years old when surveyed) } \\
\hline Years of education & $\begin{array}{l}11.331 \\
(4.413)\end{array}$ & $\begin{array}{l}15.416 \\
(3.748)\end{array}$ & $\begin{array}{l}11.510 \\
(3.276)\end{array}$ & $\begin{array}{c}8.530 \\
(3.434)\end{array}$ \\
\hline University degree & $\begin{array}{c}0.196 \\
(0.384)\end{array}$ & $\begin{array}{c}0.516 \\
(0.501)\end{array}$ & $\begin{array}{c}0.110 \\
(0.313)\end{array}$ & $\begin{array}{c}0.032 \\
(0.176)\end{array}$ \\
\hline Manager or professional & $\begin{array}{c}0.136 \\
(0.330)\end{array}$ & $\begin{array}{c}0.306 \\
(0.462)\end{array}$ & $\begin{array}{c}0.105 \\
(0.307)\end{array}$ & $\begin{array}{c}0.033 \\
(0.178)\end{array}$ \\
\hline Monthly gross wage (2016 US\$) & $\begin{array}{l}1,359 \\
(974)\end{array}$ & $\begin{array}{c}1,900 \\
(1242)\end{array}$ & $\begin{array}{l}1,153 \\
(788)\end{array}$ & $\begin{array}{c}946 \\
(629)\end{array}$ \\
\hline Referred to current job by school network & $\begin{array}{c}0.006 \\
(0.084)\end{array}$ & $\begin{array}{c}0.015 \\
(0.123)\end{array}$ & $\begin{array}{c}0.008 \\
(0.091)\end{array}$ & $\begin{array}{c}0.000 \\
-\end{array}$ \\
\hline Live birth by age 18 & $\begin{array}{c}0.105 \\
(0.307)\end{array}$ & $\begin{array}{c}0.019 \\
(0.137)\end{array}$ & $\begin{array}{c}0.112 \\
(0.316)\end{array}$ & $\begin{array}{c}0.164 \\
(0.372)\end{array}$ \\
\hline Medical insurance & $\begin{array}{c}0.301 \\
(0.451)\end{array}$ & $\begin{array}{c}0.502 \\
(0.501)\end{array}$ & $\begin{array}{c}0.254 \\
(0.436)\end{array}$ & $\begin{array}{c}0.174 \\
(0.380)\end{array}$ \\
\hline Yearly dental checkup & $\begin{array}{c}0.441 \\
(0.496)\end{array}$ & $\begin{array}{c}0.557 \\
(0.498)\end{array}$ & $\begin{array}{c}0.484 \\
(0.501)\end{array}$ & $\begin{array}{c}0.325 \\
(0.469)\end{array}$ \\
\hline Weekly gym & $\begin{array}{c}0.127 \\
(0.336)\end{array}$ & $\begin{array}{c}0.226 \\
(0.419)\end{array}$ & $\begin{array}{c}0.141 \\
(0.348)\end{array}$ & $\begin{array}{c}0.065 \\
(0.247)\end{array}$ \\
\hline Long-term index & $\begin{array}{c}0.000 \\
(1.000)\end{array}$ & $\begin{array}{c}0.801 \\
(1.120)\end{array}$ & $\begin{array}{l}-0.030 \\
(0.837)\end{array}$ & $\begin{array}{l}-0.449 \\
(0.710)\end{array}$ \\
\hline Individuals & 940 & 235 & 306 & 399 \\
\hline
\end{tabular}

Notes: All individuals who took the BSSEE between 1987 and 2011 are included in panels A and B. The gender imbalance across the school ranks reflects the fact that there is one all-girls school in the middle-ranked schools, and one all-boys school in the bottom-ranked schools. Panel C includes individuals who took the BSSEE between 1998 and 2009. This because the earliest CAPE outcome data corresponds to year 2005 which is associated with the 1998 BSSEE cohort; while the latest CAPE data corresponds to year 2016 which is associated with the 2009 BSSEE cohort. Panel D uses the full matched survey data covering BSSEE cohorts 1987-2002 (25 - 40 years old when surveyed). The Long-term index is expressed in standard deviations and combines the following outcomes: years of education, university degree, employed, manager or professional, monthly wage, medical insurance, yearly dental checkup, weekly gym, and normal BMI. Standard deviations are reported in parentheses below the means. * Qualification for tertiary education requires passing five CSEC examinations including English and mathematics. 
Table 2: Validity of Identification Strategy, School Environments, and Survey Representativeness

\begin{tabular}{|c|c|c|c|c|c|}
\hline \multirow[t]{2}{*}{ Estimation Sample: } & \multicolumn{2}{|c|}{$\begin{array}{c}\text { Administrative Data: }+/- \\
0.75 \text { SD from cutoff }\end{array}$} & \multicolumn{2}{|c|}{$\begin{array}{l}\text { Matched Survey: all } \\
\text { observations }\end{array}$} & \multirow{2}{*}{$\frac{(2)=(4)}{(5)}$} \\
\hline & (1) & (2) & (3) & (4) & \\
\hline \multicolumn{6}{|l|}{ Panel A: Cutoff manipulation test } \\
\hline Differential density & \multirow{2}{*}{\multicolumn{2}{|c|}{$\begin{array}{l}-0.8541 \\
{[0.3930]}\end{array}$}} & \multirow{2}{*}{\multicolumn{2}{|c|}{$\begin{array}{l}-0.9015 \\
{[0.3673]}\end{array}$}} & \\
\hline [p-value] & & & & & \\
\hline \multicolumn{6}{|c|}{ Panel B: Predicted Outcomes - Reduced Form } \\
\hline Predicted: CSEC qualified tertiary & \multirow{2}{*}{\multicolumn{2}{|c|}{$\begin{array}{r}<0.001 \\
(0.004)\end{array}$}} & \multirow{2}{*}{\multicolumn{2}{|c|}{$\begin{array}{c}0.001 \\
(0.007)\end{array}$}} & \\
\hline [prediction R2 = 0.12] & & & & & \\
\hline Predicted: CAPE associate & \multicolumn{2}{|c|}{$<0.001$} & \multicolumn{2}{|c|}{$<0.001$} & \\
\hline [prediction R2 $=0.05$ ] & \multicolumn{2}{|c|}{$(0.002)$} & \multicolumn{2}{|c|}{$(0.004)$} & \\
\hline \multicolumn{3}{|l|}{ Predicted: Long-term index } & \multicolumn{2}{|c|}{0.019} & \\
\hline [prediction R2 = 0.22] & & & & 19) & \\
\hline \multicolumn{6}{|l|}{ Panel C: First Stage } \\
\hline Attended preferred school & $\begin{array}{c}0.745 \\
(0.010)\end{array}$ & $\begin{array}{c}0.744 \\
(0.010)\end{array}$ & $\begin{array}{c}0.745 \\
(0.028)\end{array}$ & $\begin{array}{c}0.744 \\
(0.028)\end{array}$ & 0.975 \\
\hline \multicolumn{6}{|c|}{ Panel D: School Environments Effects - 2SLS } \\
\hline Peers BSSEE score & $\begin{array}{c}0.250 \\
(0.014)\end{array}$ & $\begin{array}{c}0.254 \\
(0.012)\end{array}$ & $\begin{array}{c}0.256 \\
(0.023)\end{array}$ & $\begin{array}{c}0.247 \\
(0.022)\end{array}$ & 0.757 \\
\hline BSSEE coef. of variation & $\begin{array}{l}-0.010 \\
(0.001)\end{array}$ & $\begin{array}{l}-0.010 \\
(0.001)\end{array}$ & $\begin{array}{l}-0.012 \\
(0.002)\end{array}$ & $\begin{array}{l}-0.009 \\
(0.002)\end{array}$ & 0.452 \\
\hline Cohort size & $\begin{array}{l}-12.901 \\
(2.852)\end{array}$ & $\begin{array}{l}-13.226 \\
(2.237)\end{array}$ & $\begin{array}{l}-13.344 \\
(4.057)\end{array}$ & $\begin{array}{l}-10.797 \\
(3.589)\end{array}$ & 0.433 \\
\hline \multicolumn{6}{|c|}{ Panel E: Survey Response Rate - $2 S L S$} \\
\hline Responded survey & $\begin{array}{l}-0.003 \\
(0.003)\end{array}$ & $\begin{array}{l}-0.004 \\
(0.003)\end{array}$ & & & \\
\hline Observations & 184,648 & 184,648 & 5,610 & 5,610 & \\
\hline Sociodemographics & Yes & Yes & Yes & Yes & \\
\hline BSSEE cubic spline & Yes & Yes & Yes & Yes & \\
\hline Cutoff fixed effects & Yes & Yes & Yes & Yes & \\
\hline Preferences fixed effects & No & Yes & No & Yes & \\
\hline $\begin{array}{l}\text { Notes: Panel A reports the results of the M } \\
\text { ficients on the 'Above' indicator resulting } \\
\text { 2SLS coefficients on 'Attend' a preferred } \\
\text { system (1) - (2)). Models in Panel B do } \\
\text { predicting the outcomes. Estimated standar } \\
\text { controls include student gender and parish } \\
\text { of sampling probability to reflect survey d } \\
\text { reported in columns (2) and (4). Sample co }\end{array}$ & $\begin{array}{l}\mathrm{d} \text { errors in p } \\
\text { fixed-effects } \\
\text { esign. Colu }\end{array}$ & $\begin{array}{l}\text { toff manipulati } \\
\text { m models as in } \\
\text { Above' as the e } \\
\text { references as th } \\
\text { thesis are cluste } \\
\text { gressions in co } \\
\text { (5) reports the }\end{array}$ & $\begin{array}{l}\text { st. Panels I } \\
\text { tion (1). Pa } \\
\text { ded instrun } \\
\text { lectivity of } \\
\text { at the indivi } \\
\text { is (3) and ( } \\
\text { lue of a tes }\end{array}$ & $\begin{array}{l}\text { nd C report } \\
\text { ls D and E } \mathrm{r} \\
\text { nt (resulting } \\
\text { references } \mathrm{u} \\
\text { al level. Soc } \\
\text { are weightec } \\
\text { or the equal } \\
\text { years old w }\end{array}$ & $\begin{array}{l}\text { nated coef- } \\
\text { t estimated } \\
n \text { equation } \\
\text { used when } \\
\text { mographic } \\
\text { the inverse } \\
\text { f estimates } \\
\text { surveyed). }\end{array}$ \\
\hline
\end{tabular}


Table 3: 2SLS Effects on Outcomes and Mechanisms

\begin{tabular}{|c|c|c|c|c|c|}
\hline & \multicolumn{2}{|c|}{ All } & \multirow{2}{*}{$\frac{\text { Women }}{(3)}$} & \multirow{2}{*}{$\begin{array}{c}\text { Men } \\
(4)\end{array}$} & \multirow{2}{*}{$\frac{(3)=(4)}{(5)}$} \\
\hline & (1) & (2) & & & \\
\hline \multicolumn{6}{|c|}{ Panel A: CSEC Performance. Sample: BSSEE cohorts 1998 - 2009 (Administrative data +/- 0.75 SD from cutoff) } \\
\hline \multirow[t]{2}{*}{ Took at least 1 subject } & 0.002 & 0.000 & 0.005 & -0.005 & 0.592 \\
\hline & $(0.010)$ & $(0.010)$ & $(0.013)$ & $(0.015)$ & \\
\hline \multirow[t]{2}{*}{ Qualified for tertiary } & -0.017 & -0.017 & -0.019 & -0.014 & 0.788 \\
\hline & $(0.010)$ & $(0.010)$ & $(0.017)$ & $(0.013)$ & \\
\hline Observations & 106,701 & 106,701 & 54,649 & 52,052 & \\
\hline \multicolumn{6}{|c|}{ Panel B: CAPE Performance. Sample: BSSEE cohorts 1998 - 2009 (Administrative data +/- 0.75 SD from cutoff) } \\
\hline \multirow[t]{2}{*}{ Took at least 1 unit } & 0.019 & 0.019 & 0.018 & 0.019 & 0.980 \\
\hline & (0.009) & $(0.009)$ & $(0.015)$ & $(0.011)$ & \\
\hline \multirow[t]{2}{*}{ Earned Associate's Degree } & 0.021 & 0.021 & 0.026 & 0.016 & 0.476 \\
\hline & $(0.007)$ & $(0.007)$ & $(0.012)$ & $(0.008)$ & \\
\hline Observations & 106,701 & 106,701 & 54,649 & 52,052 & \\
\hline \multicolumn{6}{|c|}{ Panel C: Survey Sample BSSEE Cohorts 1987 - 2002 (25 - 40 years old when surveyed - all observations) } \\
\hline \multirow[t]{2}{*}{ Long-term index } & 0.189 & 0.187 & 0.298 & 0.089 & 0.073 \\
\hline & $(0.058)$ & $(0.057)$ & $(0.085)$ & $(0.078)$ & \\
\hline \multirow[t]{2}{*}{ Educational attainment index } & 0.101 & 0.108 & 0.376 & -0.129 & 0.006 \\
\hline & $(0.092)$ & $(0.092)$ & $(0.144)$ & $(0.115)$ & \\
\hline \multirow[t]{2}{*}{ Labor market index } & 0.17 & 0.181 & 0.389 & $<0.001$ & 0.022 \\
\hline & $(0.086)$ & $(0.082)$ & $(0.121)$ & $(0.116)$ & \\
\hline \multirow[t]{2}{*}{ Health index } & 0.221 & 0.217 & 0.207 & 0.224 & 0.889 \\
\hline & $(0.062)$ & $(0.060)$ & $(0.088)$ & $(0.082)$ & \\
\hline Observations & 5,610 & 5,610 & 2,616 & 2,994 & \\
\hline \multicolumn{6}{|c|}{ Panel D: Vocational Training. Sample: BSSEE cohorts 1987 - 2002 (25 - 40 years old when surveyed) } \\
\hline \multirow[t]{2}{*}{ Technical/Vocational degree } & 0.017 & 0.025 & -0.008 & 0.049 & 0.499 \\
\hline & $(0.048)$ & $(0.044)$ & $(0.052)$ & $(0.067)$ & \\
\hline Observations & 5,277 & 5,277 & 2,510 & 2,767 & \\
\hline \multicolumn{6}{|c|}{ Panel E: Social Networks. Sample: BSSEE cohorts 1987 - 2002 (25 - 40 years old when surveyed) } \\
\hline \multirow[t]{2}{*}{ Referred to current job by school network } & 0.038 & 0.037 & 0.043 & 0.033 & 0.777 \\
\hline & $(0.017)$ & $(0.017)$ & $(0.026)$ & $(0.022)$ & \\
\hline Observations & 4,003 & 4,003 & 1,772 & 2,231 & \\
\hline \multicolumn{6}{|c|}{ Panel F: Teen Motherhood. Sample: BSSEE cohorts 1987 - 2002 (25 - 40 years old when surveyed) } \\
\hline \multirow[t]{2}{*}{ Live birth by age 17} & & & -0.057 & & \\
\hline & & & $(0.025)$ & & \\
\hline \multirow[t]{2}{*}{ Live birth by age 18} & & & -0.062 & & \\
\hline & & & $(0.032)$ & & \\
\hline Observations & & & 2,306 & & \\
\hline Sociodemographics & Yes & Yes & Yes & Yes & \\
\hline BSSEE cubic spline & Yes & Yes & Yes & Yes & \\
\hline Cutoff fixed effects & Yes & Yes & Yes & Yes & \\
\hline Preferences fixed effects & No & Yes & Yes & Yes & \\
\hline \multicolumn{6}{|c|}{$\begin{array}{l}\text { Notes: This table reports estimated 2SLS coefficients on 'Attend' a preferred school using 'Above' as the excluded instrument (resulting } \\
\text { from equation system (1) - (2) in the text). Estimated standard errors in parenthesis are clustered at the individual level. Sociodemographic } \\
\text { controls include student gender and parish fixed-effects. Panels A and B correspond to BSSEE cohorts that have both CSEC and CAPE } \\
\text { data available (BSSEE cohorts } 1998 \text { - 2009). Panels C, D, E and F use the matched survey data covering BSSEE cohorts 1987-2002 (25 } \\
\text { - } 40 \text { years old when surveyed). All regressions estimated with survey data are weighted by the inverse of sampling probability to reflect } \\
\text { survey design. Summary Indexes are expressed in standard deviations and combine the following outcomes: Educational attainment } \\
\text { (years of education, university degree); Labor market (employed, manager or professional, monthly wage); Health (medical insurance, } \\
\text { yearly dental checkup, weekly gym, normal BMI); Long-term (all outcomes included in the previous indexes). Column (5) reports the } \\
\text { p-value of a test for the equality of estimates reported in columns (3) and (4). }\end{array}$} \\
\hline
\end{tabular}




\section{Appendix A. Appendix Figures and Tables}

Figure A1. 2SLS Effects by Bandwidth
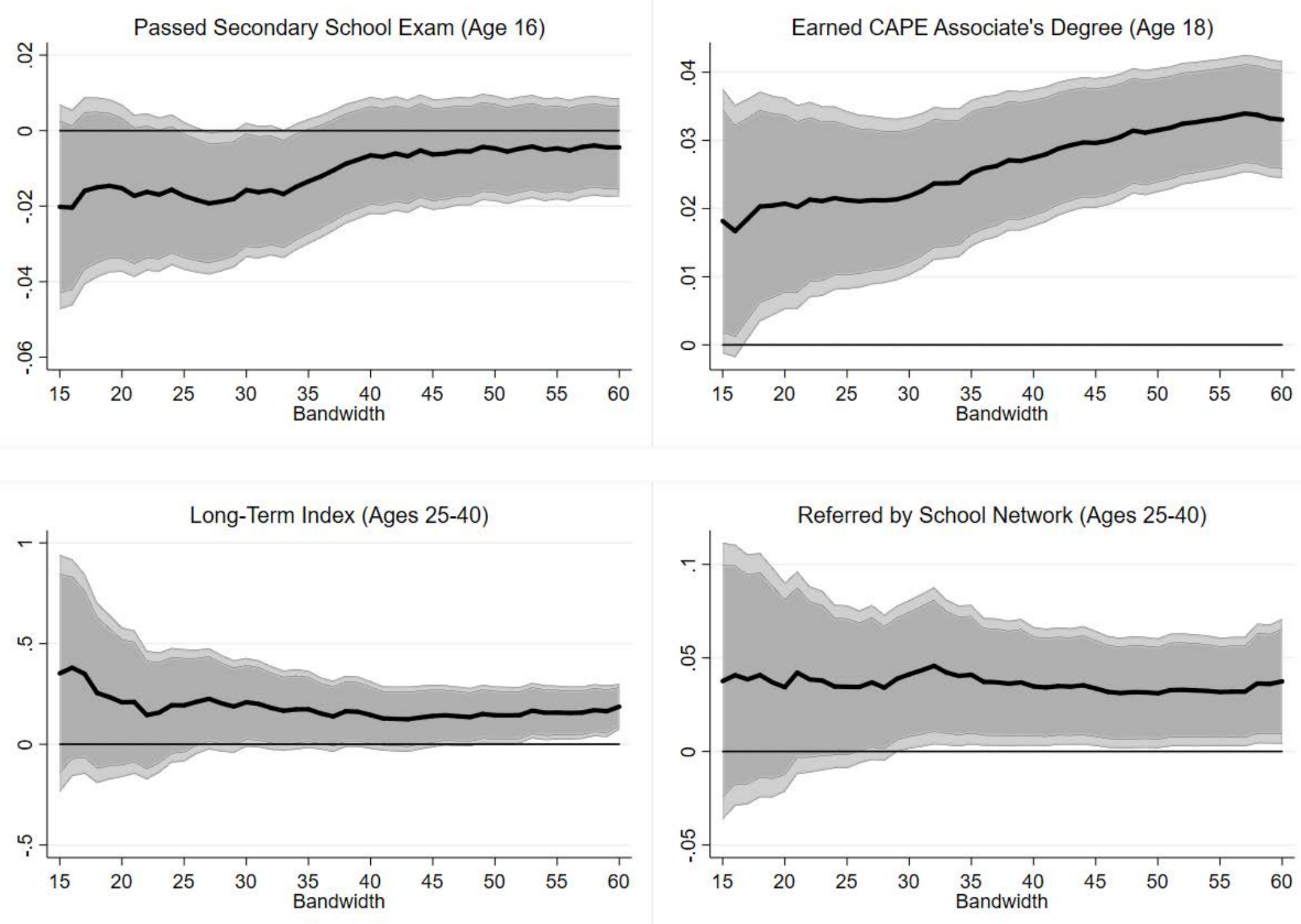

Notes: This figure depicts estimated 2SLS coefficients on 'Attend' a preferred school using 'Above' as the excluded instrument (resulting from equation system (1) - (2) in the text). The estimated 2SLS effects are reported for each bandwidth between $+/-15(+/-0.6 \mathrm{sd})$ and $+/-60(+/-2.5 \mathrm{sd})$. The 90 (95) percent confidence interval of the estimated effects is presented in dark (light) gray. 


\section{Figure A2. Cutoff Falsification Test (Long-Term Index)}

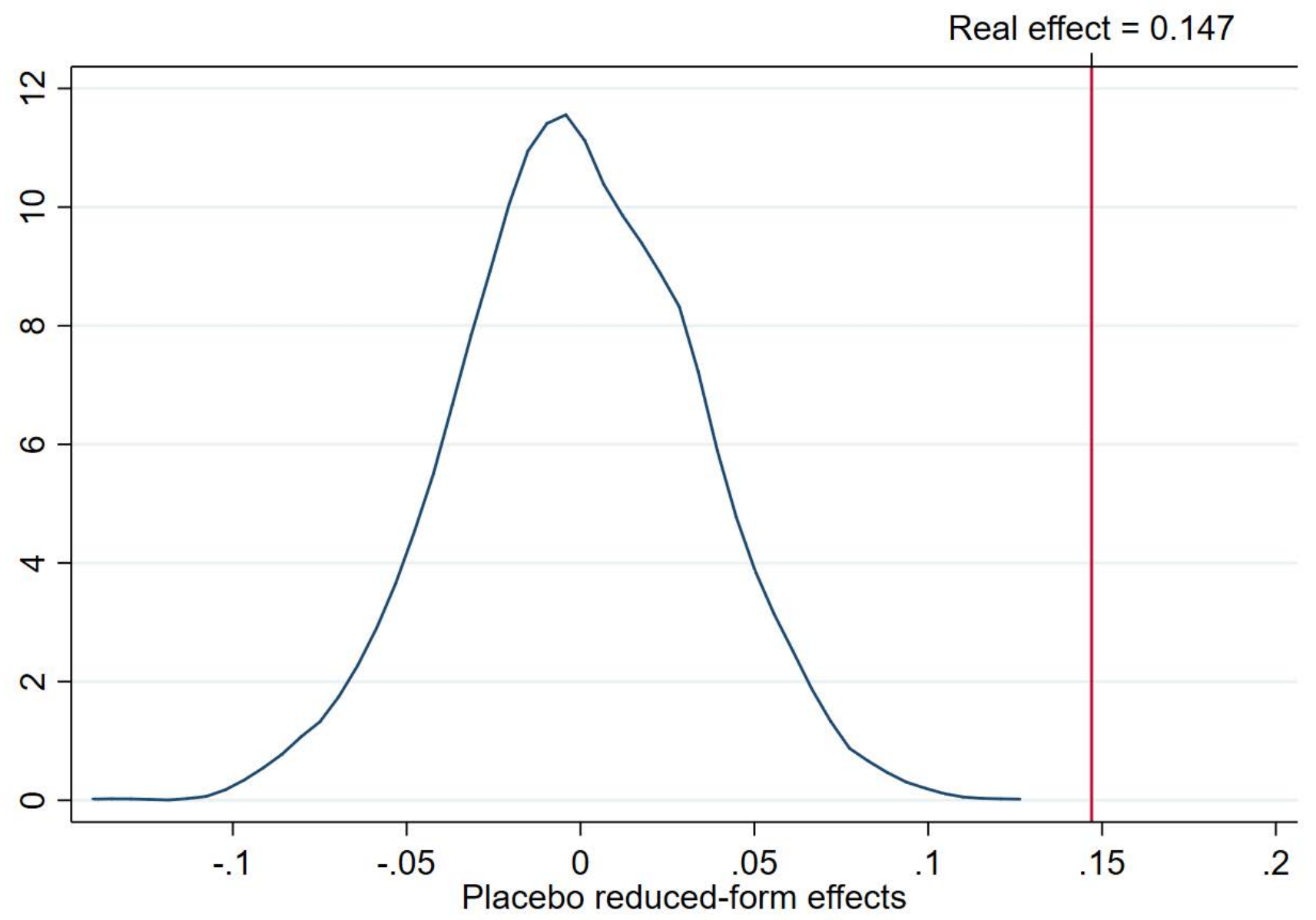

Notes: This figure depicts the distribution of 2,000 placebo estimated coefficients on the 'Above' indicator resulting from reduced-form models as in equation (1) along with the real estimated reduced-form effect on the Long-Term Index (equivalent to 0.147 standard deviations with $p$-value $<0.01$ ). Each placebo estimate was generated with the following steps: (1) A randomly chosen cutoff admission score was generated for each applicant pool (i.e. applicants to each school-year); (2) A placebo relative score and 'Above' indicator were generated with respect to the randomly chosen admission cutoff; (3) A reduced form model was estimated using the placebo relative scores and the 'Above' indicator. 
Table A1: Survey Representativeness

\begin{tabular}{|c|c|c|c|}
\hline \multirow[t]{2}{*}{ Survey Status: } & Not Surveyed & $\begin{array}{l}\text { Matched Face to } \\
\text { Face to Survey }\end{array}$ & $(1)=(2)$ \\
\hline & (1) & (2) & (3) \\
\hline \multicolumn{4}{|l|}{ Panel A: Sociodemographics } \\
\hline Female & $\begin{array}{c}0.497 \\
(0.500)\end{array}$ & $\begin{array}{c}0.483 \\
(0.500)\end{array}$ & 0.346 \\
\hline Month of birth: Jan - Mar & $\begin{array}{c}0.241 \\
(0.428)\end{array}$ & $\begin{array}{c}0.239 \\
(0.424)\end{array}$ & 0.814 \\
\hline Month of birth: Apr - Jun & $\begin{array}{l}0.218 \\
(0.413)\end{array}$ & $\begin{array}{c}0.210 \\
(0.410)\end{array}$ & 0.604 \\
\hline Month of birth: Jul - Sep & $\begin{array}{c}0.249 \\
(0.433)\end{array}$ & $\begin{array}{c}0.248 \\
(0.433)\end{array}$ & 0.913 \\
\hline Month of birth: Oct - Dec & $\begin{array}{c}0.292 \\
(0.454)\end{array}$ & $\begin{array}{c}0.303 \\
(0.459)\end{array}$ & 0.432 \\
\hline \multicolumn{4}{|c|}{ Panel B: Selectivity of Secondary School Choices (BSSEE score of incoming class } \\
\hline Choice 1 & $\begin{array}{c}1.164 \\
(0.622)\end{array}$ & $\begin{array}{c}1.124 \\
(0.622)\end{array}$ & 0.188 \\
\hline Choice 2 & $\begin{array}{c}0.934 \\
(0.669)\end{array}$ & $\begin{array}{c}0.898 \\
(0.681)\end{array}$ & 0.408 \\
\hline Choice 3 & $\begin{array}{c}0.891 \\
(0.587)\end{array}$ & $\begin{array}{c}0.856 \\
(0.604)\end{array}$ & 0.175 \\
\hline Choice 4 & $\begin{array}{c}0.611 \\
(0.621)\end{array}$ & $\begin{array}{c}0.562 \\
(0.637)\end{array}$ & 0.218 \\
\hline Choice 5 & $\begin{array}{c}0.334 \\
(0.660)\end{array}$ & $\begin{array}{c}0.294 \\
(0.652)\end{array}$ & 0.779 \\
\hline Choice 6 & $\begin{array}{c}0.078 \\
(0.724)\end{array}$ & $\begin{array}{c}0.029 \\
(0.699)\end{array}$ & 0.908 \\
\hline Choice 7 & $\begin{array}{l}-0.151 \\
(0.771)\end{array}$ & $\begin{array}{l}-0.214 \\
(0.761)\end{array}$ & 0.982 \\
\hline Choice 8 & $\begin{array}{l}-0.272 \\
(0.844)\end{array}$ & $\begin{array}{l}-0.331 \\
(0.854)\end{array}$ & 0.476 \\
\hline Choice 9 & $\begin{array}{l}-0.369 \\
(0.889)\end{array}$ & $\begin{array}{l}-0.432 \\
(0.896)\end{array}$ & 0.795 \\
\hline \multicolumn{4}{|c|}{ Panel C: Parish of Residency (before admission to secondary school) } \\
\hline Parish 1 & $\begin{array}{c}0.021 \\
(0.144)\end{array}$ & $\begin{array}{c}0.015 \\
(0.177)\end{array}$ & 0.062 \\
\hline Parish 2 & $\begin{array}{c}0.042 \\
(0.200)\end{array}$ & $\begin{array}{c}0.047 \\
(0.248)\end{array}$ & 0.257 \\
\hline Parish 3 & $\begin{array}{c}0.066 \\
(0.248)\end{array}$ & $\begin{array}{c}0.071 \\
(0.257)\end{array}$ & 0.532 \\
\hline
\end{tabular}


cont'd. Table A1: Survey Representativeness

\begin{tabular}{|c|c|c|c|}
\hline Parish 4 & $\begin{array}{c}0.036 \\
(0.188)\end{array}$ & $\begin{array}{c}0.031 \\
(0.208)\end{array}$ & 0.225 \\
\hline Parish 5 & $\begin{array}{c}0.036 \\
(0.186)\end{array}$ & $\begin{array}{c}0.047 \\
(0.226)\end{array}$ & 0.052 \\
\hline Parish 6 & $\begin{array}{c}0.363 \\
(0.481)\end{array}$ & $\begin{array}{c}0.354 \\
(0.451)\end{array}$ & 0.763 \\
\hline Parish 7 & $\begin{array}{c}0.023 \\
(0.149)\end{array}$ & $\begin{array}{c}0.026 \\
(0.192)\end{array}$ & 0.411 \\
\hline Parish 8 & $\begin{array}{c}0.087 \\
(0.281)\end{array}$ & $\begin{array}{c}0.085 \\
(0.291)\end{array}$ & 0.703 \\
\hline Parish 9 & $\begin{array}{c}0.077 \\
(0.267)\end{array}$ & $\begin{array}{c}0.088 \\
(0.287)\end{array}$ & 0.189 \\
\hline Parish 10 & $\begin{array}{c}0.047 \\
(0.211)\end{array}$ & $\begin{array}{c}0.045 \\
(0.236)\end{array}$ & 0.784 \\
\hline Parish 11 & $\begin{array}{c}0.198 \\
(0.399)\end{array}$ & $\begin{array}{c}0.190 \\
(0.372)\end{array}$ & 0.268 \\
\hline \multicolumn{4}{|c|}{ Panel D: CSEC Performance (after 5 years of secondary school) } \\
\hline Took at least 1 subject & $\begin{array}{c}0.676 \\
(0.468)\end{array}$ & $\begin{array}{c}0.692 \\
(0.436)\end{array}$ & 0.232 \\
\hline Number of subjects taken & $\begin{array}{c}3.036 \\
(3.328)\end{array}$ & $\begin{array}{c}3.268 \\
(3.291)\end{array}$ & 0.120 \\
\hline Number of subjects passed & $\begin{array}{c}2.188 \\
(2.912)\end{array}$ & $\begin{array}{c}2.282 \\
(2.809)\end{array}$ & 0.633 \\
\hline Qualified for tertiary & $\begin{array}{c}0.268 \\
(0.443)\end{array}$ & $\begin{array}{c}0.285 \\
(0.445)\end{array}$ & 0.456 \\
\hline Individuals & 93,846 & 1,545 & \\
\hline \multicolumn{4}{|c|}{ Panel E: CAPE Performance (after 2 years of post-secondary studies) } \\
\hline Took at least 1 unit & $\begin{array}{c}0.152 \\
(0.359)\end{array}$ & $\begin{array}{c}0.159 \\
(0.351)\end{array}$ & 0.731 \\
\hline Number of units taken & $\begin{array}{c}0.944 \\
(2.467)\end{array}$ & $\begin{array}{c}1.003 \\
(2.359)\end{array}$ & 0.714 \\
\hline Number of units passed & $\begin{array}{c}0.866 \\
(2.340)\end{array}$ & $\begin{array}{c}0.906 \\
(2.220)\end{array}$ & 0.830 \\
\hline Earned Associate's Degree & $\begin{array}{c}0.080 \\
(0.272)\end{array}$ & $\begin{array}{c}0.085 \\
(0.261)\end{array}$ & 0.884 \\
\hline Individuals & 43,192 & 792 & \\
\hline
\end{tabular}

Notes: All individuals who took the BSSEE between 1987 and 2011 are included in panels A, B, C, and D. However, panel E only includes individuals who took the BSSEE between 1998 and 2009. This because the earliest CAPE outcome data corresponds to year 2005 which is associated with the 1998 BSSEE cohort; while the latest CAPE data corresponds to year 2016 which is associated with the 2009 BSSEE cohort. Standard deviations are reported in parentheses below the means. Column (1) reports means and standard deviations of individuals who were not surveyed. Column (2) reports means and standard deviations of individuals who were surveyed and matched with the BSSEE administrative dataset. Estimates in column (2) are weighted by the inverse of sampling probability to reflect survey design. Column (3) reports the p-value of a test for the equality of means reported in columns (1) and (2) adjusting for BSSEE cohorts fixed effects. 
Table A2: 2SLS Effects on Secondary and Tertiary Examinations - Alternative Samples

\begin{tabular}{|c|c|c|c|c|c|c|c|}
\hline \multirow{2}{*}{ Estimation Sample: } & \multicolumn{2}{|c|}{ All } & \multicolumn{2}{|c|}{ Women } & \multicolumn{2}{|c|}{ Men } & \multirow{2}{*}{$\begin{array}{c}(4)=(6) \\
(7)\end{array}$} \\
\hline & (1) & (2) & (3) & (4) & (5) & $(6)$ & \\
\hline \multicolumn{8}{|c|}{ Panel A: CSEC Performance. Sample: BSSEE cohorts 1987 - 2002 (Administrative data +/- 0.75 SD from cutoff) } \\
\hline \multirow[t]{2}{*}{ Took at least 1 subject } & -0.02 & -0.019 & -0.009 & -0.008 & -0.03 & -0.029 & 0.279 \\
\hline & $(0.010)$ & $(0.010)$ & $(0.013)$ & $(0.013)$ & $(0.015)$ & $(0.015)$ & \\
\hline \multirow[t]{2}{*}{ Number of subjects taken } & -0.121 & -0.116 & -0.014 & -0.006 & -0.237 & -0.237 & 0.057 \\
\hline & $(0.061)$ & $(0.061)$ & $(0.086)$ & $(0.086)$ & $(0.086)$ & $(0.086)$ & \\
\hline \multirow[t]{2}{*}{ Number of subjects passed } & -0.071 & -0.069 & 0.005 & 0.006 & -0.162 & -0.16 & 0.110 \\
\hline & $(0.052)$ & $(0.052)$ & $(0.076)$ & $(0.076)$ & $(0.071)$ & $(0.071)$ & \\
\hline \multirow[t]{2}{*}{ Qualified for tertiary } & -0.004 & -0.004 & 0.003 & 0.002 & -0.012 & -0.011 & 0.440 \\
\hline & $(0.009)$ & $(0.009)$ & $(0.013)$ & $(0.013)$ & $(0.012)$ & $(0.012)$ & \\
\hline Observations & 184,648 & 184,648 & 94,385 & 94,385 & 90,263 & 90,263 & \\
\hline \multicolumn{8}{|c|}{ Panel B: CSEC Performance. Sample: BSSEE cohorts 1987 - 2002 (Full matched survey observations) } \\
\hline \multirow{2}{*}{ Took at least 1 subject } & 0.039 & 0.041 & 0.124 & 0.072 & -0.048 & 0.010 & 0.358 \\
\hline & $(0.045)$ & $(0.037)$ & $(0.062)$ & $(0.045)$ & $(0.064)$ & $(0.052)$ & \\
\hline \multirow[t]{2}{*}{ Number of subjects taken } & -0.174 & -0.005 & 0.301 & 0.330 & -0.582 & -0.287 & 0.167 \\
\hline & $(0.266)$ & $(0.230)$ & $(0.347)$ & $(0.286)$ & $(0.389)$ & $(0.344)$ & \\
\hline \multirow[t]{2}{*}{ Number of subjects passed } & -0.049 & -0.022 & 0.463 & 0.299 & -0.481 & -0.286 & 0.134 \\
\hline & $(0.239)$ & $(0.199)$ & $(0.327)$ & $(0.272)$ & $(0.336)$ & $(0.277)$ & \\
\hline \multirow[t]{2}{*}{ Qualified for tertiary } & 0.021 & 0.028 & 0.066 & 0.020 & -0.020 & 0.036 & 0.835 \\
\hline & $(0.044)$ & $(0.036)$ & $(0.062)$ & $(0.053)$ & $(0.062)$ & $(0.051)$ & \\
\hline Observations & 5,610 & 5,610 & 2,616 & 2,616 & 2,994 & 2,994 & \\
\hline \multicolumn{8}{|c|}{ Panel C: CAPE Performance. Sample: BSSEE cohorts 1998 - 2002 (Administrative data $+/-0.75$ SD from cutoff) } \\
\hline \multirow[t]{2}{*}{ Took at least 1 unit } & 0.014 & 0.016 & 0.007 & 0.008 & 0.021 & 0.022 & 0.609 \\
\hline & $(0.013)$ & $(0.013)$ & $(0.021)$ & $(0.021)$ & $(0.016)$ & $(0.016)$ & \\
\hline \multirow[t]{2}{*}{ Number of units taken } & 0.153 & 0.158 & 0.078 & 0.076 & 0.217 & 0.228 & 0.351 \\
\hline & $(0.081)$ & $(0.081)$ & $(0.132)$ & $(0.132)$ & $(0.096)$ & $(0.096)$ & \\
\hline \multirow[t]{2}{*}{ Number of units passed } & 0.13 & 0.135 & 0.071 & 0.067 & 0.178 & 0.19 & 0.424 \\
\hline & $(0.076)$ & $(0.076)$ & $(0.125)$ & $(0.126)$ & $(0.089)$ & $(0.089)$ & \\
\hline \multirow[t]{2}{*}{ Earned Associate's Degree } & 0.014 & 0.014 & 0.017 & 0.016 & 0.010 & 0.011 & 0.750 \\
\hline & $(0.009)$ & $(0.009)$ & $(0.015)$ & $(0.015)$ & $(0.010)$ & $(0.010)$ & \\
\hline Observations & 45,885 & 45,885 & 23,306 & 23,306 & 22,579 & 22,579 & \\
\hline Sociodemographics & Yes & Yes & Yes & Yes & Yes & Yes & \\
\hline BSSEE cubic spline & Yes & Yes & Yes & Yes & Yes & Yes & \\
\hline Cutoff fixed effects & Yes & Yes & Yes & Yes & Yes & Yes & \\
\hline Preferences fixed effects & No & Yes & No & Yes & No & Yes & \\
\hline
\end{tabular}


Table A3: Reduced Form Estimates on Baseline Characteristics

\begin{tabular}{|c|c|c|c|c|c|c|}
\hline \multirow{3}{*}{ Estimation Sample: } & \multicolumn{3}{|c|}{$\begin{array}{c}\text { Administrative Data: +/- } 0.75 \text { SD from } \\
\text { cutoff }\end{array}$} & \multicolumn{3}{|c|}{ Matched Face to Face Survey } \\
\hline & All & Women & Men & All & Women & Men \\
\hline & (1) & (2) & (3) & (4) & (5) & (6) \\
\hline \multicolumn{7}{|c|}{ Panel A: Month of Birth } \\
\hline January & $\begin{array}{c}0.008 \\
(0.005)\end{array}$ & $\begin{array}{l}-0.004 \\
(0.007)\end{array}$ & $\begin{array}{c}0.022 \\
(0.007)\end{array}$ & $\begin{array}{l}-0.016 \\
(0.020)\end{array}$ & $\begin{array}{l}-0.038 \\
(0.022)\end{array}$ & $\begin{array}{l}-0.008 \\
(0.026)\end{array}$ \\
\hline February & $\begin{array}{l}-0.007 \\
(0.004)\end{array}$ & $\begin{array}{c}0.002 \\
(0.006)\end{array}$ & $\begin{array}{l}-0.016 \\
(0.006)\end{array}$ & $\begin{array}{l}-0.032 \\
(0.024)\end{array}$ & $\begin{array}{c}-0.012 \\
(0.027)\end{array}$ & $\begin{array}{l}-0.027 \\
(0.027)\end{array}$ \\
\hline March & $\begin{array}{l}-0.001 \\
(0.004)\end{array}$ & $\begin{array}{c}0.003 \\
(0.006)\end{array}$ & $\begin{array}{l}-0.006 \\
(0.007)\end{array}$ & $\begin{array}{c}0.032 \\
(0.022)\end{array}$ & $\begin{array}{l}-0.014 \\
(0.021)\end{array}$ & $\begin{array}{c}0.043 \\
(0.030)\end{array}$ \\
\hline April & $\begin{array}{l}<0.001 \\
(0.004)\end{array}$ & $\begin{array}{c}0.005 \\
(0.006)\end{array}$ & $\begin{array}{l}-0.005 \\
(0.006)\end{array}$ & $\begin{array}{c}0.013 \\
(0.023)\end{array}$ & $\begin{array}{l}-0.019 \\
(0.033)\end{array}$ & $\begin{array}{c}0.037 \\
(0.022)\end{array}$ \\
\hline May & $\begin{array}{l}-0.001 \\
(0.005)\end{array}$ & $\begin{array}{l}-0.004 \\
(0.006)\end{array}$ & $\begin{array}{c}0.001 \\
(0.007)\end{array}$ & $\begin{array}{c}0.010 \\
(0.022)\end{array}$ & $\begin{array}{c}0.031 \\
(0.027)\end{array}$ & $\begin{array}{l}-0.028 \\
(0.023)\end{array}$ \\
\hline June & $\begin{array}{c}0.004 \\
(0.004)\end{array}$ & $\begin{array}{l}<0.001 \\
(0.006)\end{array}$ & $\begin{array}{c}0.009 \\
(0.006)\end{array}$ & $\begin{array}{c}0.007 \\
(0.022)\end{array}$ & $\begin{array}{c}0.007 \\
(0.027)\end{array}$ & $\begin{array}{l}-0.020 \\
(0.022)\end{array}$ \\
\hline July & $\begin{array}{l}-0.003 \\
(0.004)\end{array}$ & $\begin{array}{l}-0.001 \\
(0.006)\end{array}$ & $\begin{array}{l}-0.005 \\
(0.006)\end{array}$ & $\begin{array}{c}0.011 \\
(0.022)\end{array}$ & $\begin{array}{c}0.002 \\
(0.025)\end{array}$ & $\begin{array}{c}0.020 \\
(0.024)\end{array}$ \\
\hline August & $\begin{array}{c}0.002 \\
(0.005)\end{array}$ & $\begin{array}{c}0.005 \\
(0.006)\end{array}$ & $\begin{array}{l}-0.002 \\
(0.007)\end{array}$ & $\begin{array}{l}-0.007 \\
(0.018)\end{array}$ & $\begin{array}{c}0.014 \\
(0.023)\end{array}$ & $\begin{array}{l}-0.007 \\
(0.023)\end{array}$ \\
\hline September & $\begin{array}{c}0.001 \\
(0.005)\end{array}$ & $\begin{array}{l}-0.003 \\
(0.007)\end{array}$ & $\begin{array}{c}0.006 \\
(0.007)\end{array}$ & $\begin{array}{c}0.014 \\
(0.021)\end{array}$ & $\begin{array}{l}-0.014 \\
(0.022)\end{array}$ & $\begin{array}{c}0.026 \\
(0.024)\end{array}$ \\
\hline October & $\begin{array}{l}-0.001 \\
(0.005)\end{array}$ & $\begin{array}{c}0.007 \\
(0.007)\end{array}$ & $\begin{array}{l}-0.009 \\
(0.007)\end{array}$ & $\begin{array}{l}-0.025 \\
(0.023)\end{array}$ & $\begin{array}{l}-0.004 \\
(0.027)\end{array}$ & $\begin{array}{l}-0.048 \\
(0.026)\end{array}$ \\
\hline November & $\begin{array}{c}0.001 \\
(0.005)\end{array}$ & $\begin{array}{l}-0.009 \\
(0.007)\end{array}$ & $\begin{array}{c}0.011 \\
(0.007)\end{array}$ & $\begin{array}{l}-0.016 \\
(0.020)\end{array}$ & $\begin{array}{c}0.024 \\
(0.025)\end{array}$ & $\begin{array}{l}-0.007 \\
(0.025)\end{array}$ \\
\hline December & $\begin{array}{c}-0.003 \\
(0.005)\end{array}$ & $\begin{array}{l}-0.001 \\
(0.007)\end{array}$ & $\begin{array}{l}-0.005 \\
(0.007)\end{array}$ & $\begin{array}{c}0.008 \\
(0.025)\end{array}$ & $\begin{array}{c}0.023 \\
(0.028)\end{array}$ & $\begin{array}{c}0.019 \\
(0.030)\end{array}$ \\
\hline Panel B: Selectivity & f Secondc & ry School & es (BSSEE Sco & f incomil & g class) & \\
\hline Choice 1 & $\begin{array}{c}0.001 \\
(0.001)\end{array}$ & $\begin{array}{c}0.001 \\
(0.001)\end{array}$ & $\begin{array}{c}0.001 \\
(0.001)\end{array}$ & $\begin{array}{l}-0.002 \\
(0.004)\end{array}$ & $\begin{array}{c}0.001 \\
(0.004)\end{array}$ & $\begin{array}{c}0.003 \\
(0.005)\end{array}$ \\
\hline Choice 2 & $\begin{array}{l}<0.001 \\
(0.001)\end{array}$ & $\begin{array}{c}0.001 \\
(0.001)\end{array}$ & $\begin{array}{l}-0.001 \\
(0.001)\end{array}$ & $\begin{array}{c}0.001 \\
(0.004)\end{array}$ & $\begin{array}{l}<0.001 \\
(0.003)\end{array}$ & $\begin{array}{l}-0.013 \\
(0.005)\end{array}$ \\
\hline Choice 3 & $\begin{array}{l}<0.001 \\
(0.001)\end{array}$ & $\begin{array}{l}-0.001 \\
(0.001)\end{array}$ & $\begin{array}{l}<0.001 \\
(0.001)\end{array}$ & $\begin{array}{c}0.007 \\
(0.004)\end{array}$ & $\begin{array}{c}0.006 \\
(0.004)\end{array}$ & $\begin{array}{c}0.004 \\
(0.005)\end{array}$ \\
\hline Choice 4 & $\begin{array}{l}-0.002 \\
(0.001)\end{array}$ & $\begin{array}{l}-0.001 \\
(0.002)\end{array}$ & $\begin{array}{l}-0.002 \\
(0.002)\end{array}$ & $\begin{array}{c}0.002 \\
(0.005)\end{array}$ & $\begin{array}{c}0.003 \\
(0.005)\end{array}$ & $\begin{array}{l}-0.000 \\
(0.006)\end{array}$ \\
\hline
\end{tabular}


cont'd. Table A3: Reduced Form Estimates on Baseline Characteristics

\begin{tabular}{|c|c|c|c|c|c|c|}
\hline Choice 5 & $\begin{array}{l}<0.001 \\
(0.001)\end{array}$ & $\begin{array}{c}0.001 \\
(0.002)\end{array}$ & $\begin{array}{l}-0.001 \\
(0.002)\end{array}$ & $\begin{array}{c}-0.008 \\
(0.006)\end{array}$ & $\begin{array}{c}-0.012 \\
(0.007)\end{array}$ & $\begin{array}{c}-0.01 \\
(0.005)\end{array}$ \\
\hline Choice 6 & $\begin{array}{c}-0.002 \\
(0.001)\end{array}$ & $\begin{array}{l}-0.002 \\
(0.002)\end{array}$ & $\begin{array}{l}-0.001 \\
(0.002)\end{array}$ & $\begin{array}{c}0.001 \\
(0.006)\end{array}$ & $\begin{array}{c}0.002 \\
(0.005)\end{array}$ & $\begin{array}{l}-0.005 \\
(0.007)\end{array}$ \\
\hline Choice 7 & $\begin{array}{l}-0.001 \\
(0.002)\end{array}$ & $\begin{array}{l}<0.001 \\
(0.002)\end{array}$ & $\begin{array}{l}-0.002 \\
(0.002)\end{array}$ & $\begin{array}{c}0.011 \\
(0.007)\end{array}$ & $\begin{array}{c}0.017 \\
(0.006)\end{array}$ & $\begin{array}{l}-0.002 \\
(0.006)\end{array}$ \\
\hline Choice 8 & $\begin{array}{c}0.001 \\
(0.002)\end{array}$ & $\begin{array}{l}<0.001 \\
(0.002)\end{array}$ & $\begin{array}{c}0.002 \\
(0.002)\end{array}$ & $\begin{array}{l}<0.001 \\
(0.006)\end{array}$ & $\begin{array}{c}-0.002 \\
(0.008)\end{array}$ & $\begin{array}{c}0.004 \\
(0.006)\end{array}$ \\
\hline Choice 9 & $\begin{array}{l}-0.002 \\
(0.002)\end{array}$ & $\begin{array}{l}-0.003 \\
(0.003)\end{array}$ & $\begin{array}{l}-0.001 \\
(0.003)\end{array}$ & $\begin{array}{c}0.012 \\
(0.007)\end{array}$ & $\begin{array}{c}0.019 \\
(0.007)\end{array}$ & $\begin{array}{c}0.011 \\
(0.008)\end{array}$ \\
\hline \multicolumn{7}{|c|}{ Panel C: Parish of Residency (before admission to secondary school) } \\
\hline Parish 1 & $\begin{array}{l}<0.001 \\
(0.001)\end{array}$ & $\begin{array}{l}<0.001 \\
(0.001)\end{array}$ & $\begin{array}{l}<0.001 \\
(0.002)\end{array}$ & $\begin{array}{l}-0.004 \\
(0.003)\end{array}$ & $\begin{array}{c}<0.001 \\
(<0.001)\end{array}$ & $\begin{array}{l}-0.008 \\
(0.005)\end{array}$ \\
\hline Parish 2 & $\begin{array}{l}<0.001 \\
(0.001)\end{array}$ & $\begin{array}{l}<0.001 \\
(0.001)\end{array}$ & $\begin{array}{l}<0.001 \\
(0.002)\end{array}$ & $\begin{array}{l}-0.002 \\
(0.002)\end{array}$ & $\begin{array}{c}<0.001 \\
(<0.001)\end{array}$ & $\begin{array}{l}-0.007 \\
(0.005)\end{array}$ \\
\hline Parish 3 & $\begin{array}{l}<0.001 \\
(0.001)\end{array}$ & $\begin{array}{l}<0.001 \\
(0.001)\end{array}$ & $\begin{array}{c}0.001 \\
(0.002)\end{array}$ & $\begin{array}{l}-0.002 \\
(0.002)\end{array}$ & $\begin{array}{c}<0.001 \\
(<0.001)\end{array}$ & $\begin{array}{l}-0.008 \\
(0.005)\end{array}$ \\
\hline Parish 4 & $\begin{array}{l}<0.001 \\
(0.001)\end{array}$ & $\begin{array}{l}<0.001 \\
(0.001)\end{array}$ & $\begin{array}{l}-0.001 \\
(0.002)\end{array}$ & $\begin{array}{l}-0.003 \\
(0.003)\end{array}$ & $\begin{array}{c}<0.001 \\
(<0.001)\end{array}$ & $\begin{array}{l}-0.003 \\
(0.004)\end{array}$ \\
\hline Parish 5 & $\begin{array}{l}<0.001 \\
(0.001)\end{array}$ & $\begin{array}{l}<0.001 \\
(0.001)\end{array}$ & $\begin{array}{c}0.001 \\
(0.002)\end{array}$ & $\begin{array}{l}-0.003 \\
(0.003)\end{array}$ & $\begin{array}{c}<0.001 \\
(<0.001)\end{array}$ & $\begin{array}{l}-0.008 \\
(0.005)\end{array}$ \\
\hline Parish 6 & $\begin{array}{l}<0.001 \\
(0.001)\end{array}$ & $\begin{array}{l}<0.001 \\
(0.001)\end{array}$ & $\begin{array}{l}<0.001 \\
(0.002)\end{array}$ & $\begin{array}{l}-0.003 \\
(0.003)\end{array}$ & $\begin{array}{c}<0.001 \\
(<0.001)\end{array}$ & $\begin{array}{l}-0.007 \\
(0.005)\end{array}$ \\
\hline Parish 7 & $\begin{array}{l}-0.001 \\
(0.001)\end{array}$ & $\begin{array}{l}<0.001 \\
(0.001)\end{array}$ & $\begin{array}{c}-0.001 \\
(0.002)\end{array}$ & $\begin{array}{l}-0.003 \\
(0.002)\end{array}$ & $\begin{array}{c}<0.001 \\
(<0.001)\end{array}$ & $\begin{array}{l}-0.008 \\
(0.005)\end{array}$ \\
\hline Parish 8 & $\begin{array}{l}<0.001 \\
(0.001)\end{array}$ & $\begin{array}{l}<0.001 \\
(0.001)\end{array}$ & $\begin{array}{l}<0.001 \\
(0.002)\end{array}$ & $\begin{array}{l}-0.004 \\
(0.003)\end{array}$ & $\begin{array}{c}<0.001 \\
(<0.001)\end{array}$ & $\begin{array}{l}-0.010 \\
(0.006)\end{array}$ \\
\hline Parish 9 & $\begin{array}{l}<0.001 \\
(0.001)\end{array}$ & $\begin{array}{l}<0.001 \\
(0.001)\end{array}$ & $\begin{array}{c}0.001 \\
(0.002)\end{array}$ & $\begin{array}{l}-0.003 \\
(0.003)\end{array}$ & $\begin{array}{c}<0.001 \\
(<0.001)\end{array}$ & $\begin{array}{l}-0.009 \\
(0.006)\end{array}$ \\
\hline Parish 10 & $\begin{array}{l}-0.001 \\
(0.001)\end{array}$ & $\begin{array}{l}<0.001 \\
(0.001)\end{array}$ & $\begin{array}{l}-0.001 \\
(0.002)\end{array}$ & $\begin{array}{l}-0.002 \\
(0.002)\end{array}$ & $\begin{array}{c}<0.001 \\
(<0.001)\end{array}$ & $\begin{array}{l}-0.006 \\
(0.004)\end{array}$ \\
\hline Parish 11 & $\begin{array}{l}<0.001 \\
(0.001)\end{array}$ & $\begin{array}{l}<0.001 \\
(0.001)\end{array}$ & $\begin{array}{l}<0.001 \\
(0.002)\end{array}$ & $\begin{array}{l}-0.003 \\
(0.003)\end{array}$ & $\begin{array}{c}<0.001 \\
(<0.001)\end{array}$ & $\begin{array}{l}-0.009 \\
(0.006)\end{array}$ \\
\hline BSSEE cubic spline & Yes & Yes & Yes & Yes & Yes & Yes \\
\hline Cutoff fixed effects & Yes & Yes & Yes & Yes & Yes & Yes \\
\hline Observations & 184,648 & 94,385 & 90,263 & 5,610 & 2,616 & 2,994 \\
\hline
\end{tabular}

Notes: This table reports estimated coefficients on the 'Above' indicator resulting from reduced form models as in equation (1) of the text. Estimated standard errors in parenthesis are clustered at the individual level. Sample corresponds to BSSEE cohorts 1987 - 2002 (25 - 40 years old when surveyed). Regressions in columns 4-6 are weighted by the inverse of sampling probability to reflect survey design. 


\section{Table A4: Reduced Form Estimates on Predicted Outcomes}

\begin{tabular}{|c|c|c|c|c|c|}
\hline & $\begin{array}{l}\text { All } \\
(1)\end{array}$ & $\frac{\text { Women }}{(2)}$ & $\frac{\text { Men }}{(3)}$ & $\frac{(2)=(3)}{(4)}$ & $\frac{\text { Prediction R2 }}{(5)}$ \\
\hline \multicolumn{6}{|c|}{ Panel A: Predicted CSEC Performance. BSSEE cohorts 1998 - 2009 (Administrative data +/- 0.75 SD from cutoff) } \\
\hline Predicted: Took at least 1 subject & $\begin{array}{l}<0.001 \\
(0.002)\end{array}$ & $\begin{array}{l}<0.001 \\
(0.003)\end{array}$ & $\begin{array}{l}-0.001 \\
(0.004)\end{array}$ & 0.978 & 0.21 \\
\hline Predicted: Number of subjects taken & $\begin{array}{l}-0.014 \\
(0.016)\end{array}$ & $\begin{array}{l}-0.008 \\
(0.025)\end{array}$ & $\begin{array}{l}-0.013 \\
(0.020)\end{array}$ & 0.883 & 0.26 \\
\hline Predicted: Number of subjects passed & $\begin{array}{l}-0.013 \\
(0.013)\end{array}$ & $\begin{array}{l}-0.009 \\
(0.021)\end{array}$ & $\begin{array}{l}-0.010 \\
(0.016)\end{array}$ & 0.951 & 0.21 \\
\hline Predicted: Qualified for tertiary & $\begin{array}{l}-0.001 \\
(0.002)\end{array}$ & $\begin{array}{l}-0.001 \\
(0.003)\end{array}$ & $\begin{array}{l}-0.001 \\
(0.002)\end{array}$ & 0.864 & 0.12 \\
\hline Observations & 106,701 & 54,649 & 52,052 & & \\
\hline \multicolumn{6}{|c|}{ Panel B: Predicted CAPE Performance. BSSEE cohorts 1998 - 2009 (Administrative data +/- 0.75 SD from cutoff) } \\
\hline Predicted: Took at least 1 unit & $\begin{array}{c}-0.001 \\
(0.001)\end{array}$ & $\begin{array}{l}<0.001 \\
(0.002)\end{array}$ & $\begin{array}{l}-0.001 \\
(0.001)\end{array}$ & 0.834 & 0.08 \\
\hline Predicted: Number of units taken & $\begin{array}{l}-0.006 \\
(0.007)\end{array}$ & $\begin{array}{l}-0.004 \\
(0.010)\end{array}$ & $\begin{array}{l}-0.005 \\
(0.009)\end{array}$ & 0.948 & 0.08 \\
\hline Predicted: Number of units passed & $\begin{array}{l}-0.005 \\
(0.006)\end{array}$ & $\begin{array}{l}-0.004 \\
(0.009)\end{array}$ & $\begin{array}{l}-0.004 \\
(0.008)\end{array}$ & 0.965 & 0.08 \\
\hline Predicted: Earned Associate's Degree & $\begin{array}{l}<0.001 \\
(0.001)\end{array}$ & $\begin{array}{l}<0.001 \\
(0.001)\end{array}$ & $\begin{array}{l}<0.001 \\
(0.001)\end{array}$ & 0.960 & 0.05 \\
\hline Observations & 106,701 & 54,649 & 52,052 & & \\
\hline \multicolumn{6}{|c|}{ Panel C: Predicted Indexes. BSSEE cohorts 1987 - 2002 (25 - 40 Years old at Survey - all observations) } \\
\hline Predicted: Long-term index & $\begin{array}{c}0.019 \\
(0.019)\end{array}$ & $\begin{array}{c}0.013 \\
(0.030)\end{array}$ & $\begin{array}{c}0.019 \\
(0.023)\end{array}$ & 0.885 & 0.22 \\
\hline Predicted: Educational attainment index & $\begin{array}{c}0.029 \\
(0.030)\end{array}$ & $\begin{array}{c}0.023 \\
(0.043)\end{array}$ & $\begin{array}{c}0.026 \\
(0.039)\end{array}$ & 0.949 & 0.23 \\
\hline Predicted: Labor market index & $\begin{array}{c}0.004 \\
(0.025)\end{array}$ & $\begin{array}{c}0.022 \\
(0.034)\end{array}$ & $\begin{array}{l}-0.019 \\
(0.035)\end{array}$ & 0.398 & 0.17 \\
\hline Predicted: Health index & $\begin{array}{c}0.027 \\
(0.019)\end{array}$ & $\begin{array}{c}0.006 \\
(0.027)\end{array}$ & $\begin{array}{c}0.048 \\
(0.025)\end{array}$ & 0.258 & 0.17 \\
\hline Observations & 5,598 & 2,613 & 2,985 & & \\
\hline BSSEE cubic spline & Yes & Yes & Yes & & \\
\hline Cutoff fixed effects & Yes & Yes & Yes & & \\
\hline
\end{tabular}

Notes: This table reports estimated coefficients on the 'Above' indicator resulting from reduced form models as in equation (1) of the text. Estimated standard errors in parenthesis are clustered at the individual level. Samples in Panels A and B correspond to BSSEE cohorts that have both CSEC and CAPE data available (BSSEE cohorts 1998 - 2009). This because the earliest CAPE outcome data corresponds to year 2005 which is associated with the 1998 BSSEE cohort; while the latest CAPE data corresponds to year 2016 which is associated with the 2009 BSSEE cohort. Panel C shows estimated effects on predicted longer term indexes obtained from the matched survey data covering BSSEE cohorts 1987-2002 (25-40 years old when surveyed). Regressions do not control for preferences as the selectivity of preferences were used when predicting the outcomes. Regressions in Panel $\mathrm{C}$ are weighted by the inverse of sampling probability to reflect survey design. Column (4) reports the p-value of a test for the equality of estimates reported in columns (2) and (3). Column (5) reports the adjusted coefficient of determination of the prediction regression for each outcome. 


\section{Table A5: 2SLS Effects on CSEC and CAPE Outcomes}

\begin{tabular}{|c|c|c|c|c|c|}
\hline & \multicolumn{2}{|c|}{ All } & \multirow{2}{*}{$\frac{\text { Women }}{(3)}$} & \multirow{2}{*}{$\begin{array}{c}\text { Men } \\
(4)\end{array}$} & \multirow{2}{*}{$\frac{(3)=(4)}{(5)}$} \\
\hline & (1) & (2) & & & \\
\hline \multicolumn{6}{|c|}{ Panel A: CSEC Performance. Sample: BSSEE cohorts 1998 - 2009 (Administrative data +/- 0.75 SD from cutoff) } \\
\hline \multirow[t]{2}{*}{ Took at least 1 subject } & 0.002 & 0.000 & 0.005 & -0.005 & 0.592 \\
\hline & $(0.010)$ & $(0.010)$ & $(0.013)$ & $(0.015)$ & \\
\hline \multirow[t]{2}{*}{ Number of subjects taken } & -0.128 & -0.129 & 0.077 & -0.314 & 0.007 \\
\hline & $(0.072)$ & $(0.072)$ & $(0.105)$ & $(0.099)$ & \\
\hline \multirow[t]{2}{*}{ Number of subjects passed } & -0.027 & -0.025 & 0.108 & -0.146 & 0.035 \\
\hline & $(0.060)$ & $(0.060)$ & $(0.091)$ & $(0.078)$ & \\
\hline \multirow[t]{2}{*}{ Qualified for tertiary } & -0.017 & -0.017 & -0.019 & -0.014 & 0.788 \\
\hline & $(0.010)$ & $(0.010)$ & $(0.017)$ & $(0.013)$ & \\
\hline Observations & 106,701 & 106,701 & 54,649 & 52,052 & \\
\hline \multicolumn{6}{|c|}{ Panel B: CAPE Performance. Sample: BSSEE cohorts 1998 - 2009 (Administrative data +/- 0.75 SD from cutoff) } \\
\hline \multirow[t]{2}{*}{ Took at least 1 unit } & 0.019 & 0.019 & 0.018 & 0.019 & 0.980 \\
\hline & $(0.009)$ & $(0.009)$ & $(0.015)$ & $(0.011)$ & \\
\hline \multirow[t]{2}{*}{ Number of units taken } & 0.201 & 0.196 & 0.164 & 0.226 & 0.624 \\
\hline & $(0.062)$ & $(0.062)$ & $(0.103)$ & $(0.071)$ & \\
\hline \multirow[t]{2}{*}{ Number of units passed } & 0.195 & 0.191 & 0.17 & 0.21 & 0.739 \\
\hline & $(0.059)$ & $(0.059)$ & $(0.098)$ & $(0.066)$ & \\
\hline \multirow[t]{2}{*}{ Earned Associate's Degree } & 0.021 & 0.021 & 0.026 & 0.016 & 0.476 \\
\hline & $(0.007)$ & $(0.007)$ & $(0.012)$ & $(0.008)$ & \\
\hline Observations & 106,701 & 106,701 & 54,649 & 52,052 & \\
\hline Sociodemographics & Yes & Yes & Yes & Yes & \\
\hline BSSEE cubic spline & Yes & Yes & Yes & Yes & \\
\hline Cutoff fixed effects & Yes & Yes & Yes & Yes & \\
\hline Preferences fixed effects & No & Yes & Yes & Yes & \\
\hline
\end{tabular}

Notes: This table reports estimated 2SLS coefficients on 'Attend' a preferred school using 'Above' as the excluded instrument (resulting from equation system (1) - (2) in the text). Estimated standard errors in parenthesis are clustered at the individual level. Sociodemographic controls include student gender and parish fixed-effects. The population corresponds to BSSEE cohorts that have both CSEC and CAPE data available (BSSEE cohorts 1998 - 2009). Column (5) reports the p-value of a test for the equality of estimates reported in columns (3) and (4). 
Table A6: 2SLS Effects on Educational Attainment and Labor Market Indicators

\begin{tabular}{|c|c|c|c|c|c|c|c|}
\hline \multirow{3}{*}{ BSSEE Cohorts: } & \multicolumn{7}{|c|}{1987 - 2002: 25 - 40 Years old at Survey (Full Matched Data) } \\
\hline & \multicolumn{2}{|c|}{ All } & \multicolumn{2}{|c|}{ Women } & \multicolumn{2}{|c|}{ Men } & \multirow{2}{*}{$\frac{(4)=(6)}{(7)}$} \\
\hline & (1) & (2) & (3) & (4) & (5) & (6) & \\
\hline \multicolumn{8}{|c|}{ Panel A: Educational Attainment } \\
\hline Years of education & $\begin{array}{c}0.615 \\
(0.386)\end{array}$ & $\begin{array}{c}0.677 \\
(0.382)\end{array}$ & $\begin{array}{c}1.409 \\
(0.573)\end{array}$ & $\begin{array}{c}1.644 \\
(0.575)\end{array}$ & $\begin{array}{l}-0.189 \\
(0.529)\end{array}$ & $\begin{array}{l}-0.238 \\
(0.514)\end{array}$ & 0.015 \\
\hline University degree & $\begin{array}{c}0.043 \\
(0.044)\end{array}$ & $\begin{array}{c}0.045 \\
(0.043)\end{array}$ & $\begin{array}{c}0.168 \\
(0.070)\end{array}$ & $\begin{array}{c}0.174 \\
(0.070)\end{array}$ & $\begin{array}{l}-0.063 \\
(0.052)\end{array}$ & $\begin{array}{l}-0.066 \\
(0.052)\end{array}$ & 0.006 \\
\hline Observations & 5,277 & 5,277 & 2,510 & 2,510 & 2,767 & 2,767 & \\
\hline \multicolumn{8}{|c|}{ Panel B: Main Occupation } \\
\hline Employed & $\begin{array}{c}0.097 \\
(0.054)\end{array}$ & $\begin{array}{c}0.101 \\
(0.051)\end{array}$ & $\begin{array}{c}0.14 \\
(0.074)\end{array}$ & $\begin{array}{c}0.133 \\
(0.067)\end{array}$ & $\begin{array}{c}0.065 \\
(0.078)\end{array}$ & $\begin{array}{c}0.076 \\
(0.076)\end{array}$ & 0.582 \\
\hline Unemployed & $\begin{array}{c}-0.022 \\
(0.044)\end{array}$ & $\begin{array}{c}-0.039 \\
(0.040)\end{array}$ & $\begin{array}{c}-0.11 \\
(0.063)\end{array}$ & $\begin{array}{c}-0.126 \\
(0.055)\end{array}$ & $\begin{array}{c}0.052 \\
(0.061)\end{array}$ & $\begin{array}{c}0.037 \\
(0.057)\end{array}$ & 0.043 \\
\hline Out of labor force & $\begin{array}{l}-0.075 \\
(0.040)\end{array}$ & $\begin{array}{c}-0.062 \\
(0.039)\end{array}$ & $\begin{array}{l}-0.030 \\
(0.054)\end{array}$ & $\begin{array}{c}-0.007 \\
(0.054)\end{array}$ & $\begin{array}{l}-0.117 \\
(0.058)\end{array}$ & $\begin{array}{l}-0.114 \\
(0.057)\end{array}$ & 0.180 \\
\hline Observations & 5,610 & 5,610 & 2,616 & 2,616 & 2,994 & 2,994 & \\
\hline \multicolumn{8}{|c|}{ Panel C: Employment Quality (only employed persons) } \\
\hline Manager or professional & $\begin{array}{c}0.057 \\
(0.050)\end{array}$ & $\begin{array}{c}0.056 \\
(0.051)\end{array}$ & $\begin{array}{c}0.248 \\
(0.086)\end{array}$ & $\begin{array}{c}0.246 \\
(0.087)\end{array}$ & $\begin{array}{l}-0.094 \\
(0.058)\end{array}$ & $\begin{array}{l}-0.088 \\
(0.059)\end{array}$ & 0.002 \\
\hline Log monthly wage & $\begin{array}{c}0.176 \\
(0.101)\end{array}$ & $\begin{array}{c}0.158 \\
(0.105)\end{array}$ & $\begin{array}{c}0.42 \\
(0.172)\end{array}$ & $\begin{array}{c}0.413 \\
(0.173)\end{array}$ & $\begin{array}{l}-0.015 \\
(0.119)\end{array}$ & $\begin{array}{l}-0.043 \\
(0.123)\end{array}$ & 0.027 \\
\hline Observations & 4,048 & 4,048 & 1,774 & 1,774 & 2,274 & 2,274 & \\
\hline Sociodemographics & Yes & Yes & Yes & Yes & Yes & Yes & \\
\hline BSSEE cubic spline & Yes & Yes & Yes & Yes & Yes & Yes & \\
\hline Cutoff fixed effects & Yes & Yes & Yes & Yes & Yes & Yes & \\
\hline Preferences fixed effects & No & Yes & No & Yes & No & Yes & \\
\hline
\end{tabular}


Table A7: 2SLS Effects on Health Indicators

\begin{tabular}{|c|c|c|c|c|c|c|c|}
\hline \multirow{3}{*}{ BSSEE Cohorts: } & \multicolumn{7}{|c|}{1987 - 2002: 25 - 40 Years old at Survey (Full Matched Data) } \\
\hline & \multicolumn{2}{|c|}{ All } & \multicolumn{2}{|c|}{ Women } & \multicolumn{2}{|c|}{ Men } & \multirow{2}{*}{$\frac{(4)=(6)}{(7)}$} \\
\hline & (1) & (2) & (3) & (4) & $(5)$ & (6) & \\
\hline \multicolumn{8}{|c|}{ Panel A: Preventive Health Behaviors } \\
\hline Weekly gym & $\begin{array}{c}0.117 \\
(0.040)\end{array}$ & $\begin{array}{c}0.125 \\
(0.040)\end{array}$ & $\begin{array}{c}0.14 \\
(0.055)\end{array}$ & $\begin{array}{c}0.136 \\
(0.054)\end{array}$ & $\begin{array}{c}0.092 \\
(0.058)\end{array}$ & $\begin{array}{c}0.107 \\
(0.056)\end{array}$ & 0.706 \\
\hline Medical insurance & $\begin{array}{c}0.027 \\
(0.054)\end{array}$ & $\begin{array}{c}0.028 \\
(0.052)\end{array}$ & $\begin{array}{c}0.136 \\
(0.079)\end{array}$ & $\begin{array}{c}0.102 \\
(0.078)\end{array}$ & $\begin{array}{l}-0.065 \\
(0.073)\end{array}$ & $\begin{array}{l}-0.035 \\
(0.068)\end{array}$ & 0.190 \\
\hline Yearly dental checkup & $\begin{array}{c}0.107 \\
(0.058)\end{array}$ & $\begin{array}{c}0.111 \\
(0.058)\end{array}$ & $\begin{array}{c}0.006 \\
(0.083)\end{array}$ & $\begin{array}{c}0.043 \\
(0.080)\end{array}$ & $\begin{array}{c}0.2 \\
(0.081)\end{array}$ & $\begin{array}{c}0.176 \\
(0.081)\end{array}$ & 0.237 \\
\hline Observations & 5,610 & 5,610 & 2,616 & 2,616 & 2,994 & 2,994 & \\
\hline \multicolumn{8}{|c|}{ Panel B: Objective Health Outcomes (based on BMI) } \\
\hline Normal weight & $\begin{array}{c}0.183 \\
(0.068)\end{array}$ & $\begin{array}{c}0.167 \\
(0.067)\end{array}$ & $\begin{array}{c}0.186 \\
(0.098)\end{array}$ & $\begin{array}{c}0.2 \\
(0.098)\end{array}$ & $\begin{array}{c}0.19 \\
(0.093)\end{array}$ & $\begin{array}{c}0.129 \\
(0.087)\end{array}$ & 0.593 \\
\hline Overweight or Obese & $\begin{array}{l}-0.145 \\
(0.067)\end{array}$ & $\begin{array}{l}-0.141 \\
(0.066)\end{array}$ & $\begin{array}{l}-0.171 \\
(0.097)\end{array}$ & $\begin{array}{l}-0.191 \\
(0.095)\end{array}$ & $\begin{array}{l}-0.126 \\
(0.090)\end{array}$ & $\begin{array}{l}-0.082 \\
(0.085)\end{array}$ & 0.397 \\
\hline Underweight & $\begin{array}{l}-0.038 \\
(0.026)\end{array}$ & $\begin{array}{l}-0.026 \\
(0.024)\end{array}$ & $\begin{array}{l}-0.015 \\
(0.038)\end{array}$ & $\begin{array}{l}-0.009 \\
(0.038)\end{array}$ & $\begin{array}{l}-0.064 \\
(0.036)\end{array}$ & $\begin{array}{l}-0.047 \\
(0.030)\end{array}$ & 0.440 \\
\hline Observations & 4,361 & 4,361 & 2,146 & 2,146 & 2,215 & 2,215 & \\
\hline Sociodemographics & Yes & Yes & Yes & Yes & Yes & Yes & \\
\hline BSSEE cubic spline & Yes & Yes & Yes & Yes & Yes & Yes & \\
\hline Cutoff fixed effects & Yes & Yes & Yes & Yes & Yes & Yes & \\
\hline Preferences fixed effects & No & Yes & No & Yes & No & Yes & \\
\hline
\end{tabular}


Table A8: Sensitivity of 2SLS Effects on Main Outcomes to Alternative BSSEE Polynomial Specifications

\begin{tabular}{|c|c|c|c|c|c|c|c|c|c|}
\hline & \multicolumn{3}{|c|}{ All } & \multicolumn{3}{|c|}{ Women } & \multicolumn{3}{|c|}{ Men } \\
\hline & (1) & (2) & (3) & (4) & (5) & (6) & (7) & (8) & (9) \\
\hline \multicolumn{10}{|c|}{ Panel A: CSEC Performance. Sample: BSSEE cohorts 1998 - 2009 (Administrative data +/- 0.75 SD from cutoff) } \\
\hline \multirow[t]{2}{*}{ Took at least 1 subject } & -0.02 & -0.014 & 0.000 & -0.016 & -0.007 & 0.005 & -0.025 & -0.019 & -0.005 \\
\hline & $(0.004)$ & $(0.007)$ & $(0.010)$ & $(0.005)$ & (0.009) & $(0.013)$ & $(0.007)$ & $(0.011)$ & $(0.015)$ \\
\hline \multirow[t]{2}{*}{ Qualified for tertiary } & 0.004 & -0.012 & -0.017 & 0.004 & -0.018 & -0.019 & 0.004 & -0.007 & -0.014 \\
\hline & $(0.004)$ & $(0.007)$ & $(0.010)$ & $(0.006)$ & $(0.011)$ & $(0.017)$ & $(0.006)$ & (0.009) & $(0.013)$ \\
\hline \multicolumn{10}{|c|}{ Panel B: CAPE Performance. Sample: BSSEE cohorts 1998 - 2009 (Administrative data +/- 0.75 SD from cutoff) } \\
\hline \multirow[t]{2}{*}{ Took at least 1 unit } & 0.058 & 0.031 & 0.019 & 0.065 & 0.039 & 0.018 & 0.053 & 0.022 & 0.019 \\
\hline & $(0.004)$ & $(0.006)$ & $(0.009)$ & $(0.006)$ & $(0.010)$ & $(0.015)$ & $(0.005)$ & $(0.008)$ & $(0.011)$ \\
\hline \multirow[t]{2}{*}{ Earned Associate's Degree } & 0.049 & 0.028 & 0.021 & 0.061 & 0.041 & 0.02 & 0.03 & 0.015 & 0.016 \\
\hline & $(0.003)$ & $(0.005)$ & $(0.007)$ & $(0.004)$ & $(0.008)$ & $(0.012)$ & $(0.003)$ & $(0.005)$ & $(0.008)$ \\
\hline \multicolumn{10}{|c|}{ Panel C: Survey Sample BSSEE Cohorts 1987 - 2002 (25 - 40 years old when surveyed - all observations) } \\
\hline \multirow[t]{2}{*}{ Long-term index } & 0.121 & 0.167 & 0.187 & 0.161 & 0.274 & 0.298 & 0.084 & 0.071 & 0.089 \\
\hline & $(0.032)$ & $(0.042)$ & $(0.057)$ & $(0.050)$ & $(0.059)$ & $(0.0$ & $(0.041)$ & $(0.058)$ & $(0.078)$ \\
\hline \multirow[t]{2}{*}{ Educational attainment index } & 0.179 & 0.187 & 0.108 & 0.227 & 0.383 & 0.376 & 0.136 & 0.012 & -0.129 \\
\hline & $(0.049)$ & $(0.067)$ & $(0.092)$ & $(0.074)$ & $(0.100)$ & $(0.144)$ & $(0.066)$ & $(0.088)$ & $(0.115)$ \\
\hline \multirow[t]{2}{*}{ Labor market index } & 0.106 & 0.124 & 0.181 & 0.219 & 0.31 & 0.389 & 0.002 & -0.045 & 0.000 \\
\hline & $(0.045)$ & $(0.062)$ & $(0.082)$ & $(0.067)$ & $(0.086)$ & $(0.121)$ & $(0.062)$ & $(0.090)$ & $(0.116)$ \\
\hline \multirow[t]{2}{*}{ Health index } & 0.072 & 0.148 & 0.217 & 0.070 & 0.175 & 0.207 & 0.077 & 0.126 & 0.224 \\
\hline & $(0.041)$ & $(0.047)$ & $(0.060)$ & $(0.067)$ & $(0.070)$ & $(0.088)$ & $(0.047)$ & $(0.063)$ & $(0.082)$ \\
\hline BSSEE polynomial order & 1 & 2 & 3 & 1 & 2 & 3 & 1 & 2 & 3 \\
\hline
\end{tabular}

Notes: This table reports estimated 2SLS coefficients on 'Attend' a preferred school using 'Above' as the excluded instrument (resulting from equation system (1) - (2) in the text) using alternative polynomial specifications of the BSSEE relative score. Estimated standard errors in parenthesis are clustered at the individual level. Sociodemographic controls include student gender and parish fixed-effects. All regressions include interactions between the BSSEE polynomial and the the 'Above' indicator, cutoff fixed effects and preference fixed effects. Samples in Panels A and B correspond to BSSEE cohorts that have both CSEC and CAPE data available (BSSEE cohorts 1998 - 2009). Panel C uses the full matched survey data covering BSSEE cohorts 1987-2002 (25 - 40 years old when surveyed) and these regressions are weighted by the inverse of sampling probability to reflect survey design. Summary Indexes are expressed in standard deviations and combine the following outcomes: Educational attainment (years of education, university degree); Labor market (employed, manager or professional, monthly wage); Health (medical insurance, yearly dental checkup, weekly gym, normal BMI); Long-term (all outcomes included in the previous indexes). 
Table A9: 2SLS Effects on Main Outcomes (two-way clustering at the individual and BSSEE score levels)

\begin{tabular}{|c|c|c|c|c|c|c|c|}
\hline & \multicolumn{2}{|c|}{ All } & \multicolumn{2}{|c|}{ Women } & \multicolumn{2}{|c|}{ Men } & \multirow{2}{*}{$\begin{array}{c}(4)=(6) \\
(7)\end{array}$} \\
\hline & $(1)$ & (2) & (3) & (4) & $(5)$ & $(6)$ & \\
\hline \multicolumn{8}{|c|}{ Panel A: CSEC Performance. Sample: BSSEE cohorts 1998 - 2009 (Administrative data +/- 0.75 SD from cutoff) } \\
\hline \multirow[t]{2}{*}{ Took at least 1 subject } & 0.002 & 0.000 & 0.006 & 0.005 & -0.003 & -0.005 & 0.602 \\
\hline & $(0.010)$ & $(0.010)$ & $(0.013)$ & $(0.012)$ & $(0.015)$ & $(0.015)$ & \\
\hline \multirow[t]{2}{*}{ Qualified for tertiary } & -0.017 & -0.017 & -0.019 & -0.019 & -0.015 & -0.014 & 0.792 \\
\hline & $(0.010)$ & $(0.010)$ & $(0.016)$ & $(0.016)$ & $(0.013)$ & $(0.013)$ & \\
\hline Observations & 106,701 & 106,701 & 54,649 & 54,649 & 52,052 & 52,052 & \\
\hline \multicolumn{8}{|c|}{ Panel B: CAPE Performance. Sample: BSSEE cohorts 1998 - 2009 (Administrative data +/- 0.75 SD from cutoff) } \\
\hline \multirow[t]{2}{*}{ Took at least 1 unit } & 0.019 & 0.019 & 0.019 & 0.018 & 0.02 & 0.019 & 0.98 \\
\hline & $(0.010)$ & $(0.010)$ & $(0.015)$ & $(0.016)$ & $(0.012)$ & $(0.012)$ & \\
\hline \multirow[t]{2}{*}{ Earned Associate Degree } & 0.021 & 0.021 & 0.026 & 0.026 & 0.016 & 0.016 & 0.48 \\
\hline & $(0.007)$ & $(0.007)$ & $(0.012)$ & $(0.012)$ & $(0.008)$ & $(0.008)$ & \\
\hline Observations & 106,701 & 106,701 & 54,649 & 54,649 & 52,052 & 52,052 & \\
\hline \multicolumn{8}{|c|}{ Panel C: Survey Sample BSSEE Cohorts 1987 - 2002 (25 - 40 years old when surveyed - all observations) } \\
\hline \multirow[t]{2}{*}{ Long-term index } & 0.189 & 0.187 & 0.285 & 0.298 & 0.101 & 0.089 & 0.027 \\
\hline & $(0.052)$ & $(0.052)$ & $(0.061)$ & $(0.058)$ & $(0.081)$ & $(0.081)$ & \\
\hline \multirow[t]{2}{*}{ Educational attainment index } & 0.101 & 0.108 & 0.341 & 0.376 & -0.118 & -0.129 & 0.009 \\
\hline & $(0.090)$ & $(0.089)$ & $(0.142)$ & $(0.140)$ & $(0.123)$ & $(0.123)$ & \\
\hline \multirow[t]{2}{*}{ Labor market index } & 0.17 & 0.181 & 0.4 & 0.389 & -0.030 & $<0.001$ & 0.007 \\
\hline & $(0.074)$ & $(0.068)$ & $(0.097)$ & $(0.085)$ & $(0.117)$ & $(0.113)$ & \\
\hline \multirow[t]{2}{*}{ Health index } & 0.221 & 0.217 & 0.219 & 0.207 & 0.224 & 0.224 & 0.876 \\
\hline & $(0.058)$ & $(0.056)$ & $(0.071)$ & $(0.069)$ & $(0.088)$ & $(0.084)$ & \\
\hline Observations & 5,610 & 5,610 & 2,616 & 2,616 & 2,994 & 2,994 & \\
\hline Sociodemographics & Yes & Yes & Yes & Yes & Yes & Yes & \\
\hline BSSEE cubic spline & Yes & Yes & Yes & Yes & Yes & Yes & \\
\hline Cutoff fixed effects & Yes & Yes & Yes & Yes & Yes & Yes & \\
\hline Preferences fixed effects & No & Yes & No & Yes & No & Yes & \\
\hline
\end{tabular}

Notes: This table reports estimated 2SLS coefficients on 'Attend' a preferred school using 'Above' as the excluded instrument (resulting from equation system (1) - (2) in the text). Estimated standard errors in parenthesis are two-way clustered at the individual and BSSEE score levels. Sociodemographic controls include student gender and parish fixed-effects. Regressions in Panel C are weighted by the inverse of sampling probability to reflect survey design. Column (7) reports the p-value of a test for the equality of estimates reported in columns (4) and (6). Summary Indexes are expressed in standard deviations and combine the following outcomes: Educational attainment (years of education, university degree); Labor market (employed, manager or professional, monthly wage); Health (medical insurance, yearly dental checkup, weekly gym, normal BMI); Long-term (all outcomes included in the previous indexes). 
Table A10: 2SLS Effects on Fertility

\begin{tabular}{|c|c|c|}
\hline \multirow{2}{*}{ Sample } & \multicolumn{2}{|c|}{ Women } \\
\hline & (1) & (2) \\
\hline \multicolumn{3}{|c|}{ Panel A: Sample: BSSEE cohorts 1987 - 2002 (25 - 40 years old when surveyed) } \\
\hline \multirow[t]{2}{*}{ Baby by 25} & 0.023 & 0.018 \\
\hline & $(0.077)$ & $(0.052)$ \\
\hline \multirow[t]{2}{*}{ At least 1 baby ever } & 0.049 & -0.001 \\
\hline & $(0.071)$ & $(0.049)$ \\
\hline \multirow[t]{2}{*}{ Total fertility } & 0.032 & -0.114 \\
\hline & $(0.186)$ & $(0.134)$ \\
\hline Observations & 2,341 & 2,341 \\
\hline \multicolumn{3}{|c|}{ Panel B: Sample: BSSEE cohorts 1987 - 1992 (35 - 40 years old when surveyed) } \\
\hline \multirow[t]{2}{*}{ At least 1 baby ever } & 0.133 & 0.084 \\
\hline & $(0.105)$ & $(0.092)$ \\
\hline \multirow[t]{2}{*}{ Total fertility } & 0.504 & 0.328 \\
\hline & $(0.389)$ & $(0.329)$ \\
\hline Observations & 909 & 909 \\
\hline \multicolumn{3}{|c|}{ Panel C: Sample: BSSEE cohorts 1987 - 1991 (36-40 years old when surveyed) } \\
\hline \multirow[t]{2}{*}{ At least 1 baby ever } & 0.108 & 0.005 \\
\hline & $(0.110)$ & $(0.091)$ \\
\hline \multirow[t]{2}{*}{ Total fertility } & 0.455 & 0.393 \\
\hline & $(0.408)$ & $(0.371)$ \\
\hline Observations & 729 & 729 \\
\hline Sociodemographics & Yes & Yes \\
\hline BSSEE cubic spline & Yes & Yes \\
\hline Cutoff fixed effects & Yes & Yes \\
\hline Preferences fixed effects & No & Yes \\
\hline \multicolumn{3}{|c|}{$\begin{array}{l}\text { Notes: This table reports estimated 2SLS coefficients on 'Attend' a preferred school using } \\
\text { 'Above' as the excluded instrument (resulting from equation system (1) - (2) in the text). Es- } \\
\text { timated standard errors in parenthesis are clustered at the individual level. Sociodemographic } \\
\text { controls include student gender and parish fixed-effects. Regressions are weighted by the inverse } \\
\text { of sampling probability to reflect survey design. }\end{array}$} \\
\hline
\end{tabular}




\section{Appendix B. Meta-Analysis Methodology}

We perform meta-analysis on all publicly-available studies using quasi-random assignment to a preferred (non-charter) public school (either through lottery or selective enrollment exam). We focus on studies that examine test score impacts. Studies for the meta-analysis were obtained through a targeted literature search. This involved searching through the bibliographies of known papers that fit the inclusion criteria and a search of papers citing these papers. To locate additional papers that may have been missed using this first approach, we also conducted a keyword search on "causal" and "elite" or "selective" for additional papers. We found 17 papers that fit our criteria.

Following Borenstein et al. (2009), the meta-analytic methodology employed can be summarized in two main stages. First, the computation of the estimated effect from each study and, second, the computation of the overall average effect across all studies. For the first stage, because studies tend to report multiple estimated effects, we consider the following criteria: (i) The estimate resulting from the preferred identification strategy and model specification by the author if specified. If no preference is specified, we take into account estimates from all identification strategies used (considering the model specification with most controls within each strategy). ${ }^{23}$ (ii) Treatment on the treated effects whenever possible. If not reported, intention to treat effects are used. (iii) Test scores closer to secondary school completion (e.g. 11th grade preferred to 9th grade). (iv) Full population effects. If effects are reported only for sub-populations separately, we record all of them and compute a weighted aggregate effect. (v) Overall examination scores (of exams that evaluate mathematics and language together) if available. If not, separate scores on mathematics and language examinations are recorded and then averaged. If only one overall score of an examination that evaluates mathematics, language, and other additional subjects is available, we consider that one.

After following these criteria, some studies will have multiple effects using different identification strategies, sub-populations or examinations. Therefore, following Borenstein et al. (2009), we compute one single overall average effect for each study. For this, it is important to recognize whether different effects presented within the same study are expected to be correlated. This is the case when math and language effects are estimated for the same sample or when different identification strategies are used for the same outcomes. In such cases, we compute as the combined effect the mean of the estimated effects and we assume a correlation of 0.5 between their standard errors to compute the variance of the combined effect. If different sub-populations are used, such as gender, cohorts or regions and no overall effects are presented, then (also following Borenstein et al. (2009)) we assume them to be independent and we generate a combined effect for each study $j$

\footnotetext{
${ }^{23}$ Such is the case of Bui et al. (2014) where we use the estimated effects derived from both the RD and Admission Lottery identification strategies.
} 
by performing a fixed-effects meta-regression. This procedure estimates a weighted average effect $\left(E S_{j}\right)$ and average variance $\left(S E_{j}^{2}\right)$ for each study $j$ as follows:

$$
\begin{gathered}
E S_{j}=\frac{\sum \frac{e s_{i}}{s e_{i}^{2}}}{\sum s e_{i}^{2}} \\
S E_{j}{ }^{2}=\left(\sum \frac{1}{s e_{i}^{2}}\right)^{-1}
\end{gathered}
$$

where $e s_{i}$ denotes the $i^{t h}$ estimated effect of study $j$ and $s e_{i}{ }^{2}$ denotes the variance of such estimated effect.

In the second stage, we compute an overall average effect across all studies through a randomeffects meta-regression of all the studies' estimated effects obtained within the first stage (see Borenstein et al. (2009), chapter 12 for a detailed explanation). The random-effects meta regression estimates a weighted average effect $(\mu)$ of the included studies where the weight for each study $j$ is computed as follows:

$$
W_{j}=\frac{1}{S E_{j}^{2}+T^{2}}
$$

where $S E_{j}{ }^{2}$ is the variance of the estimated effect from study $j$ (or the within study variance) and $T^{2}$ is the between-study variance. We estimate the between-study variance using a method of moments approach.

Finally, we compute the prediction interval for the weighted average effect across all studies ,$\mu$, as follows:

$$
\mu \pm z \sqrt{T^{2}+S E^{2}}
$$

where $S E^{2}$ denotes the variance of the weighted average effect $(\mu)$ and $T^{2}$ denotes the betweenstudy variance resulting from the random-effects meta-regression of all the studies' estimated effects (estimated with a method of moments approach). The prediction interval presents the expected range of true effects in similar studies.

Our analysis includes the following studies assessing the test score effects of attending any preferred public (non-charter) secondary school: Abdulkadiroğlu et al. (2014), Abdulkadiroglu et al. (2017), Anderson et al. (2016), Ajayi (2015), Cullen et al. (2006), Deming (2011), Hastings et al. (2009), Hoekstra et al. (2018), Jackson (2010), Pop-Eleches and Urquiola (2013). In addition, we also consider the following studies assessing the test score effects of attending a preferred elite public secondary school: Barrow et al. (2017), Bui et al. (2014), Clark (2010), Dee and Lan (2015), Dustan et al. (2017), Lucas and Mbiti (2014), Park et al. (2015). 


\section{Appendix C. The Revealed Preference Ranking of Schools}

While existing studies have examined the impacts of attending a more selective school or an elite school, it is not clear that most parents actually prefer such schools. If all parents prefer more elite (or selective) schools, the lack of an elite schooling effect would speak to the choices made by all parents. Conversely, if parents hold very different views regarding what schools they prefer, then elite schools would not necessarily be preferred by many (or even most) parents. In this second scenario, the lack of an elite schooling effect would speak to the choices made by some parents, but would not speak to the choices made my most parents. Related to this, if parents agree on which schools are preferred, the benefits to attending a preferred school reflect the relative impacts of a certain set of schools. Conversely, if parents have very heterogeneous preferences for schools, the benefits to attending a preferred school might reflect student-school matching effects rather than the effectiveness of a certain set of schools relative to others. From a policy perspective, and to aid interpretation, these are important distinctions that we examine below.

To better understand parental preferences for schools, we follow Avery et al. (2013) and exploit the choice data to construct a revealed-preference ranking of secondary schools in Barbados. Intuitively, because each student lists a set of schools they wish to attend, in order of desirability, and the allocation algorithm is truth revealing among the set of choices submitted, one can determine which are more preferred schools by seeing which individual schools tend to be systematically higher in individuals' choices. The ranking approach is similar to that used for ranking players in tournaments where players are observed in several head-to-head match-ups. Schools that tend to be preferred in many head-to-head comparisons (i.e. ranked above other schools on the list) are more highly ranked, and schools that are preferred over more highly ranked schools are themselves more highly ranked. Because each list of $X$ ranked schools includes $\sum_{n=1}^{X-1}(X-n)$ such head-tohead comparisons and thousands of students submit such lists each year, constructing such rankings from the choice data is feasible. We expand on the model below.

Each student $i$, has a utility value, $U_{i j}$, for each secondary school $j$, given by (1) below.

$$
U_{i j}=\theta_{j}+\varepsilon_{i j}
$$

The parameter $\theta_{j}$ is an index of the overall desirability of school $j$, and the random error term is $\varepsilon_{i j}$. The parameter $\theta_{j}$ does not vary at the student level and therefore represents a school's average desirability. Let $\theta_{j}^{r_{i s}}$ be the desirably of the school $j$ that individual $i$ ranked $s\left(r_{i}=s\right)$ in their list of options $R_{i}$. Let $U_{i j}^{r_{i s}}$ be the utility individual $i$ gets from school $j$ that she ranked in position $s$, so that $U_{i j}^{r_{i 1}}$ is her utility from the school she ranked first, $U_{i j}^{r_{i 2}}$ her utility for the school ranked second, and so on. Because the assignment mechanism is truthfully revealing within the set of submitted choices, we make the simple behavioral assumption that higher ranked schools 
are preferred to lower ranked schools. It therefore follows that the probability that an individual $i$ submits a particular ranking over the set of listed schools is

$$
\operatorname{Pr}\left[\left(U_{i j}^{r_{i 1}}>U_{i k}^{r_{i m}}, 1<m, \forall m \in\left\{2, \ldots, R_{i}\right\}\right) \cap \ldots \cap\left(U_{i j}^{r_{i R_{i}-1}}>U_{i k}^{r_{i R_{i}}}\right)\right]
$$

As is common practice in the discrete-choice literature, we assume that $\varepsilon_{i j}$ follows an extreme value distribution so that the probability that an individual $i$ submits a particular ranking over all ranked schools is a product of standard logit formulas. The likelihood (or probability) that individual $i$ chooses ranking $\left\{r_{i 1}, r_{i 2}, \ldots, R_{i}\right\}$ is now:

$$
l_{i}(\theta)=\operatorname{Prob}\left[r_{i 1}, r_{i 2}, \ldots, R_{i}\right]=\frac{\exp \left(\theta_{j}^{r_{i 1}}\right)}{\sum_{k=1}^{R_{i}} \exp \left(\theta_{i k}^{r_{i k}}\right)} \cdot \frac{\exp \left(\theta_{j}^{r_{i 2}}\right)}{\sum_{k=2}^{R_{i}} \exp \left(\theta_{i k}^{r_{i k}}\right)} \cdots \frac{\exp \left(\theta_{j}^{r_{i R-1}}\right)}{\exp \left(\theta_{j}^{r_{i R-1}}\right)+\exp \left(\theta_{k}^{r_{i R_{i}}}\right)}
$$

The full log likelihood of observing all the choices is simply the sum of the log of the individual likelihoods across all individuals.

$$
\log L(\theta)=\sum_{i=1}^{N} \log l_{i}(\theta)
$$

One can obtain estimated preferences for each school $\hat{\theta}_{j}$ by finding the $\theta_{j}$ s that maximize the full $\log$ likelihood. This is achieved by estimating a rank-ordered logit model with a full set of indicator variables for each school in Barbados. Because proximity is a strong predictor of parents' choices, we obtained rankings based on models that both include and exclude proximity to each school choice as a covariate. Reassuringly, the rankings are identical across both models. Schools with larger $\hat{\theta}_{j}$ s are those that tend to be listed higher up in individuals' ordered lists. The school with the highest $\hat{\theta}_{j}$ will be the school that is most likely to be preferred (on average) in head-to-head comparisons with other schools. After running this model, we rank schools by their estimated desirability to obtain a revealed-preference ranking over all schools. If students who list both schools A and B tend to list school A above school B, and students who list both schools B and C tend to list school B above school C, our approach will rank school A above B and B above C.

\section{The Estimated School Rankings}

To determine whether the preference rankings are meaningful, we first establish that they are stable over time. The top five schools in 1987 remain the top five schools in 2011 with the only difference being that the top two schools swapped places. ${ }^{24}$ While there is some movement among the lower-ranked schools, the rankings are quite stable across this 25 year period. Overall, the

\footnotetext{
${ }^{24}$ Using the reveled preference rankings, the five top ranked schools in 1987 were (1) Harrison College (HC), (2) Queens College (QC), (3) Combermere School (CS), (4) St. Michaels School (SM), (5) Christ Church Foundation (CF). A quarter century later in 2011, the top ranked schools were (1) QC, (2) HC, (3) CS, (4) SM, (5) CF.
} 
correlation between the revealed preference rank in 1987 and the revealed preference rank in 2011 is 0.96. The similarity in rankings when parents can rank all schools (and therefore truthful revelation is a dominant strategy) and when they can rank up to nine schools, indicates that one can reliably infer parental preferences from choice data when parents can only rank nine choices. A scatter-plot of the rankings across these two years is presented in the left panel of Figure C1. The regression predicting the rank in 2011 based on the rank in 1987 has a slope of 0.97 and an R-squared of 0.91. The $p$-value for the test that the slope is equal to 1 is 0.7 . This suggests that the average view regarding what schools are most desirable has been very stable over time.

Having established that aggregate school rankings are stable over time, we now explore how much the average view is shared among individuals. To do this, we rank schools in each year, and then estimate the likelihood of a given school being listed as a preferred school in a given year as a function of its aggregate ranking in that year. ${ }^{25}$ If there is widespread agreement among parents about what the most desirable schools are, aggregate rankings would predict being ranked more highly by parents, and rank reversals (i.e. putting a lower-ranked school higher in one's choice list) would be uncommon. Conversely, if there is considerable heterogeneity in parents' views regarding which schools are more desirable, aggregate rankings may predict being ranked more highly by parents on average, but rank reversals would be common. The average ranking in a given year is a very strong predictor of individual choices in that year. A school is 44 percent more likely to be more highly ranked by an individual if it is one rank higher in the aggregate, 3 times as likely to be more highly ranked if it is three ranks higher in the aggregate, and 38 times as likely to be more highly ranked if it is 10 ranks higher in the aggregate.

To assuage concerns that the analysis above uses an in-sample prediction (for which there may be some mechanical correlation), we also we rank schools based on the choice lists in 1987, and then estimate the likelihood of a given school being listed as a preferred school in 2011 as a function of its ranking in 1987. We estimate this using a rank ordered logit model on the 2011 choices in which the 1987 ranking enters the model as the sole predictor. Because we use the rankings from a different year, this model will understate the extent to which the individual choices are similar to the average view. However, the patterns are very similar. The 1987 ranking is a powerful predictor of rankings in subsequent years. A school is 33 percent more likely to be more highly ranked in 2011 if it is one rank higher in 1987, 2.4 times as likely to be more highly ranked in 2011 if it is three ranks higher in 1987, and more than 19 times as likely to be more highly ranked in 2011 if it is 10 ranks higher in $1987 .^{26}$ These patterns suggests that while parents may disagree regarding which

\footnotetext{
${ }^{25}$ We estimate a rank ordered logit model in which the aggregate ranking enters the model as the sole predictor

${ }^{26}$ Put differently, a rank reversal would occur only about 42 percent of the time for schools that were one rank apart in 1987, under 30 percent of the time for schools that were four ranks apart in 1987, and less than six percent of the time for schools that were ten ranks apart. Figure $\mathrm{C} 2$ shows the estimated likelihood that a parent would rank a school above another school in 2011 as a function of the difference in the school rankings in 1987.
} 
schools are most desirable among very similarly ranked schools, there is considerable agreement regarding which group of schools are most desirable. To allow for the possibility that boys and girls may have different preferences for schools, we examined differences by student gender and the results are virtually identical. ${ }^{27}$

Because the highest-achieving students are admitted to their top choices first, if most students rank schools similarly, then the more preferred schools will also be more selective than the less preferred schools. To show that this is borne out in the data, the right panel of Figure $\mathrm{C} 1$ presents the cumulative distribution of the mean peer incoming BSSEE scores of students' school choices. The distribution of mean BSSEE scores of first-choice schools is to the right of the second-choice schools, which is to the right of the third-choice schools, and so on. That is, parents and students tend to place schools with higher-achieving peers higher up on their preference ranking. This is further evidence that most parents agree on which schools are most desirable. As above, we allow for the possibility that boys and girls may have different preferences for schools, we examined differences by student gender, and the results are virtually identical. Given that the impact of schools may differ by student gender, this is an important finding.

\footnotetext{
${ }^{27}$ We calculated revealed preference rankings pooling all BSSEE cohorts separately by gender. The correlation between girls' rankings and boys' rankings is 0.996 .
} 
Figure C1. School Choices
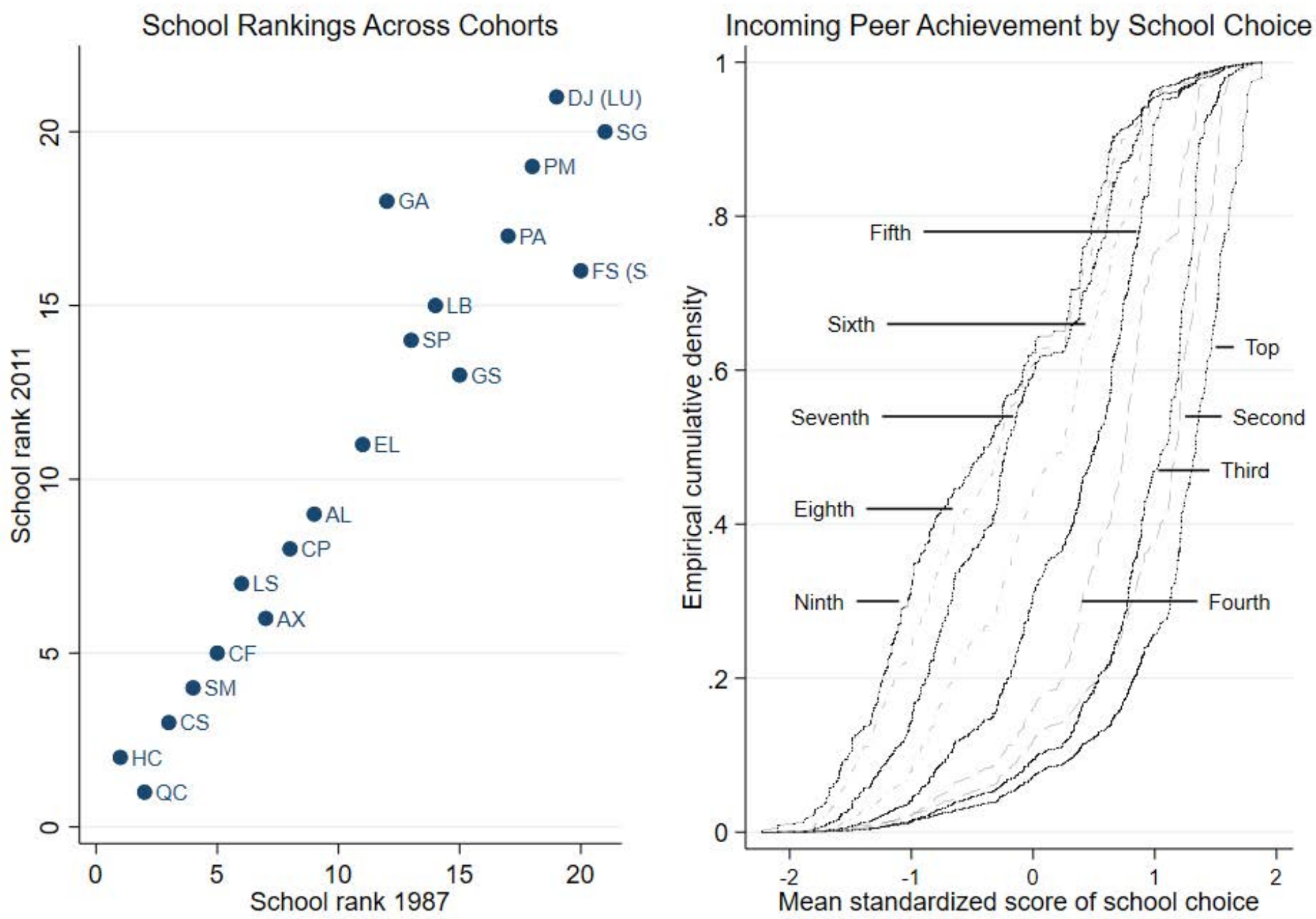
Figure C2. Probability of Rank Reversal

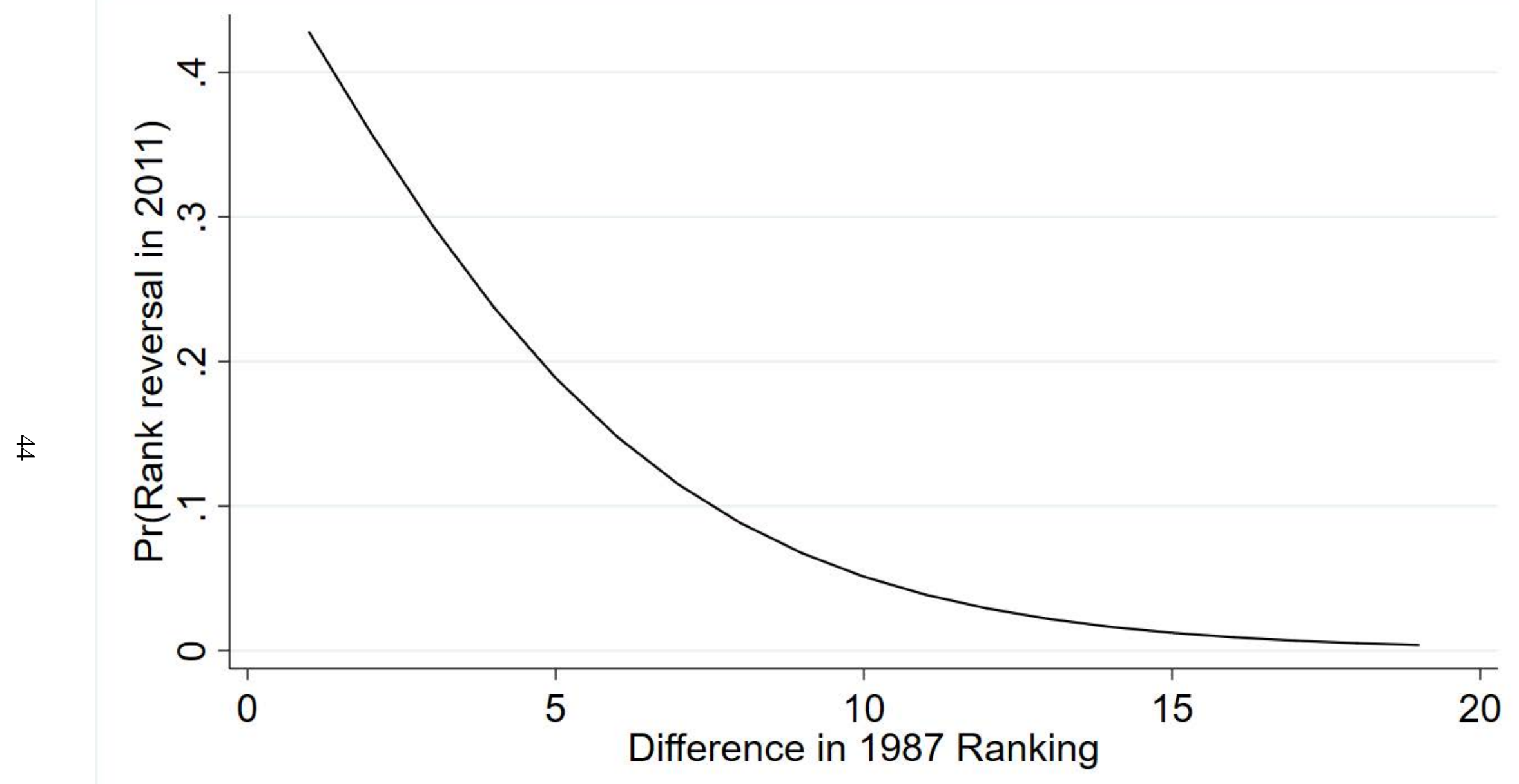




\section{Appendix D. Do the Null Effects Generalize to the Average Stu- dent?}

Because our estimated preferred school effects are based on applicants who score just above or just below the cutoff for a preferred school, this local treatment effect may not reflect the experiences of the average student at a preferred school. This limitation applies to 13 out of the 17 studies in Table 1 that rely on test score cutoffs to identify school impacts. In these studies (as here) the estimated treatment effect is the impact of being the lowest scoring student at a preferred school relative to being a more typical student at a less preferred school which may be different from the average effect of attending a preferred school relative to a less preferred school. If so, the small benefits to attending a preferred school for the marginal admit could be reconciled with strong parental preferences for such schools if the average impacts were more positive than those for the marginal student who scores just above the cutoff. Contributing to this literature methodologically, we implement a test for whether the estimated school impacts for the marginal students are similar to those for the average student. While used for a different purpose, our proposed test is similar to those used in Deming (2014) and Hastings et al. (2015) to validate observational school impacts with quasi-random variation. This test will help potentially explain the null impacts we find in Barbados and possibly other settings.

\section{The Empirical Test}

We now introduce some notation. The impact of attending school $j$ for the average student is $\mu_{j 1}$ while that for the marginal student is $\mu_{j 2}$. The outcome for marginal student $i$ at school $j$ is

$$
Y_{i j t}=\mu_{j 2}+f\left(B S E E_{i t}\right)+X_{i j t} \gamma+C_{j t}+P_{i j t}+\varepsilon_{i j t}
$$

The estimated effect on outcome $Y_{i j t}$ of scoring above the admissions cutoff for any school $j$ is $\Gamma_{j, \text { actual }}=E\left(Y_{i j t} \mid\right.$ Above $\left.=1\right)-E\left(Y_{i j t} \mid\right.$ Above $\left.=0\right)$. Substituting (11) into this expression and taking expectations, in the neighborhood of the cutoff yields

$$
E\left[\Gamma_{j, \text { actual }}\right]=E\left(\mu_{j 2} \mid \text { Above }=1\right)-E\left(\mu_{j 2} \mid \text { Above }=0\right)
$$

In expectation, the RD estimate of scoring above the cutoff for school $j$ simply reflects the difference through that cutoff in the attended school impacts for the marginal students. This is intuitive; scoring above the cutoff for school $j$ increases the likelihood of attending school $j$ and reduces the likelihood of attending the next preferred schools. If school $j$ is no more effective for the marginal admit (on average) than the next preferred schools, then the cutoff effect for school $j$ will be zero. Conversely, the cutoff for school $j$ will only have a positive impact if school $j$ is more effective at 
improving outcomes for the marginal admit (on average) than the next preferred schools.

Now consider impacts for the average admit, $\mu_{j 1}$. One can estimate the impact of school $j$ for the average student, $\mu_{j 1}$, in a value-added framework. Where $I_{i, J=j}$ is an indicator variable equal to 1 if student $i$ attends school $j$, the outcome for average student $i$ at school $j$ is

$$
Y_{i j t}=I_{i, J=j} \cdot \mu_{j 1}+f\left(B S S E E_{i t}\right)+X_{i j t} \gamma+C_{j t}+P_{i j t}+\varepsilon_{i j t}
$$

One can obtain an estimate of the value-added of school $j$ for the average attendee by estimating equation (13) by OLS. The resulting estimate $\hat{\mu}_{j 1}$ is simply a school fixed effect that reflects the school-level average outcomes after accounting for observable student characteristics such as incoming test scores, choices, and demographics. ${ }^{28}$

As discussed above, the RD estimate of scoring above the cutoff for school $j$ on outcomes reflects the difference through that cutoff in the attended school impacts (i.e. $\delta\left(\mu_{j 2}\right) / \delta($ Above)) for the marginal admits. We define $\Gamma_{j \text {,predicted }}$ as the difference through that cutoff in the estimated value-added of the attended school (i.e. $\delta\left(\hat{\mu}_{j 1}\right) / \delta$ (Above)) among those same marginal admits. If (i) the value-added estimate is unbiased such that $E\left[\hat{\mu}_{j 1}\right]=\mu_{j 1}$, and (ii) the effect of school $j$ for the marginal admit is the same as the average admit such that $\mu_{j 1}=\mu_{j 2}$, then (iii) in expectation, the change in the average estimated value-added of the school attended through the cutoff for school $j$ should be equal to the actual change in outcomes through that cutoff. ${ }^{29}$ We test this empirically by estimating $\Gamma_{j, \text { actual }}$ and $\Gamma_{j, \text { predicted }}$ for each school $j$ across all the CSEC outcomes, and then we regress one on the other. To avoid endogeneity, we use out-of-sample (or leave-year-out) estimates of school value-added. If our school value-added estimates are biased, then the slope of this regression will differ from 1 . In addition, if the school impacts are different for the marginal student from those for the average student, then this slope will also differ from 1. However, if (a) our school value-added estimates are unbiased, and (b) the school impacts are the same for the marginal student as for the average student, then the slope will be equal to $1 .^{30}$

\footnotetext{
${ }^{28}$ Under the assumption that $E\left[\varepsilon_{i j t} \mid I_{i, J=j}, B S S E E_{i t}, X_{i j t}, C_{j t}, P_{i j t}\right]=0$, this will be an unbiased estimate.

${ }^{29}$ One can estimate the impact of scoring above the cutoff for school $j$ on the average value-added of the schools students attend, $\hat{\mu}_{j 1}$, by replacing the actual outcomes with the estimated value-added of the attended school and estimating the model below.

$$
\hat{\mu}_{j 1}=\zeta_{j} \cdot \text { Above }_{i j t}+f\left(B S E E_{i t}\right)+X_{i j t} \gamma+C_{j t}+P_{i j t}+\varepsilon_{i j t}
$$

The parameter $\zeta_{j}$ is the difference in school value-added between those who score just above the cutoff for school $j$ and those who score just below. In the neighborhood of the cutoff, this is

$$
E\left[\zeta_{j} \mid X_{i}, B S E E_{i}\right]=E\left(\mu_{j 1} \mid \text { Above }=1\right)-E\left(\mu_{j 1} \mid \text { Above }=0\right)
$$

${ }^{30}$ It is possible that biases in the school effect estimates are exactly offset by differences between the marginal and average treatment effects so that the estimated coefficient appears to be 1 even when the marginal and average impacts
} 
Pooling the estimated impacts for each cutoff (preferred school) across all CSEC outcomes, we plot the estimated impacts against the difference in school value-added in Figure D1. The estimated slope is 0.97 , revealing that on average the predicted impacts are very similar to the actual impacts. The $p$-value associated with the null hypothesis that the slope is zero has a $p$-value of less than 0.001 , and the $p$-value associated with the null hypothesis that the slope is 1 has a $p$-value of 0.836 . This is compelling evidence that the null impacts on short-run test scores are not because the impact for the marginal student is more negative than that for the average student. ${ }^{31}$

differ. This would be a razor's edge result and is extraordinarily unlikely. Accordingly, we assume that the probability of such a situation is essentially zero.

${ }^{31}$ This test also serves as a validation of the school fixed effects (i.e. value-added estimates). 


\section{Figure D1. Predicted Cutoff Effects vs Actual Cutoff Effects - CSEC Outcomes}

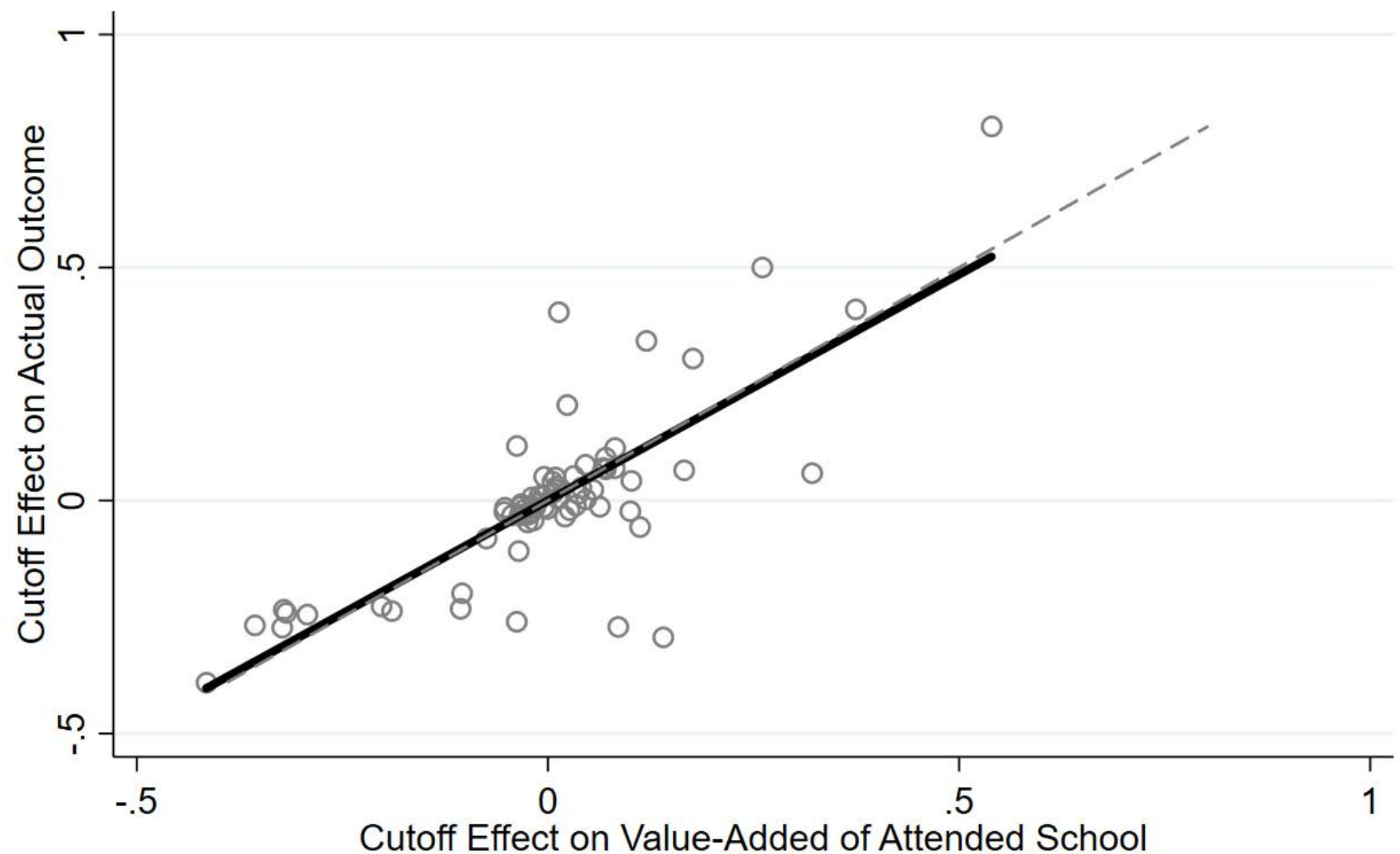

\section{$\circ$ Cutoff Effects Linear Fit $-----45^{\circ}$ Line}

Slope $=0.97:($ Slope $==0:$ pval $->0.000 ;$ Slope $==1:$ pval $->0.836)$

Notes: The X-axis represents the estimated coefficients on the 'Above' indicator resulting from equation (14); estimated for each school $j$ and for each CSEC outcome (school value-added measures enter as dependent variables). The Y-axis represents the estimated coefficients on the 'Above' indicator resulting from reduced form models as in equation (1); estimated for each school $j$ and for each CSEC outcome (individual level outcomes enter as dependent variables). 